Title: Stationary Liquid Fuel Fast Reactor SLFFR — Part II: Safety Analysis

Authors: T. Jing, Y. S. Jung, and W. S. Yang*

Affiliation: School of Nuclear Engineering, Purdue University, IN 47907, USA

Corresponding author: Won Sik Yang

E-mail address: yang494@purdue.edu

Telephone: (765) 494-4710

Mailing address: 400 Central Dr., West Lafayette, IN 47907, USA

Total Number of Pages: $\quad 30$ (including this page)

Number of Tables: $\quad 6$

Number of Figures: $\quad 17$ 


\title{
Stationary Liquid Fuel Fast Reactor SLFFR — Part II: Safety Analysis
}

\author{
T. Jing, Y. S. Jung, and W. S. Yang*
}

\begin{abstract}
Safety characteristics have been evaluated for the stationary liquid fuel fast reactor (SLFFR) proposed for effective burning of hazardous TRU elements of used nuclear fuel. In order to model the geometrical configuration and reactivity feedback mechanisms unique to SLFFR, a multi-channel safety analysis code named MUSA was developed. MUSA solves the timedependent coupled neutronics and thermal-fluidic problems. The thermal-fluidic behavior of the core is described by representing the core with one-dimensional parallel channels. The primary heat transport system is modeled by connecting compressible volumes by liquid segments. A point kinetics model with six delayed neutron groups is used to represent the fission power transients. The reactivity feedback is estimated by combining the temperature and density variations of liquid fuel, structural material and sodium coolant with the corresponding axial distributions of reactivity worth in each individual thermal-fluidic channel. Preliminary verification tests with a conventional solid fuel reactor agreed well with the reference solutions obtained with the SAS4A/SASSYS-1 code. Transient analyses of SLFFR were performed for unprotected transient over-power (UTOP), unprotected loss of heat sink (ULOHS) and unprotected loss of flow (ULOF) accidents. The results showed that the thermal expansion of liquid fuel provides sufficiently large negative feedback reactivity for passive shutdown of UTOP and ULOHS. The ULOF transient is also terminated passively with the negative reactivity introduced by the gas expansion modules installed at the core periphery. The maximum coolant temperatures have sufficient margins to the sodium boiling point for all three unprotected transient scenarios.
\end{abstract}

Key words: passive safety, fast reactor, liquid fuel reactor, unprotected accidents 


\section{Introduction}

For effective burning of hazardous TRU elements of used nuclear fuel, a transformational advanced reactor concept named the stationary liquid fuel fast reactor (SLFFR) was proposed based on a stationary molten metallic fuel (Yang and Grandy, 2012). The net consumption rate of TRU is maximized in the SLFFR by utilizing a uranium-free fuel that reduces the TRU conversion ratio to zero. Preliminary core design studies for a $1000 \mathrm{MWt}$ SLFFR using TRU-CeCo fuel, Ta-10W fuel container, and sodium coolant (Yang et al., 2013; Jing et al., 2015) showed the feasibility of achieving a zero TRU conversion ratio with sufficiently negative prompt feedbacks. A reference point design developed in these studies has been improved to enhance the safety characteristics. Several design iterations were made to provide not only the customary safety margins in design basis events, but also to deliver superior safety performance in beyond design basis events involving multiple equipment failures or unplanned operator actions (Jing et al., 2016a). Detailed neutronics and thermal-fluidic analyses were performed to evaluate the steady-state performance characteristics. Fuel cycle performances were analyzed with detailed depletion calculations and ex-core fuel cycle models. A multi-channel safety analysis code named MUSA was developed, tailored to SLFFR, and various protected and unprotected accidents were analyzed (Yang et al., 2015). The resulting, latest core design of SLFFR is described in this paper and the companion paper. The design and performance characteristics are presented in the previous paper (Jing et al., 2016b), and the safety characteristics are presented in this paper.

The SLFFR is a loop-type sodium cooled fast reactor with an innovative core design. The use of uranium-free fuel results in an almost zero or slightly positive Doppler feedback coefficient and a significantly reduced delayed neutron faction. However, the degraded reactivity coefficient of uranium-free fuel is overcome by the prompt negative reactivity feedback due to the thermal expansion of liquid metal fuel, which is several times larger in magnitude compared to that in the conventional solid metal fuel reactors. Two separate safety-grade reactivity control systems are introduced to provide sufficient shutdown margins. Gas expansion modules (GEMs), originally used in the Fast Flux Test Facility (FFTF) (Campbell, 1986), are employed to enhance the negative reactivity feedback during a postulated unprotected loss of flow accident. An orifice zoning approach is adopted to allocate the total flow rate effectively to the different regions of the core.

The liquid fuel is contained in a closed container with over 18 thousands penetrating coolant tubes. The core channel geometry is topologically inverted relative to the conventional solid fuel pin surrounded by coolant. In addition, the radial expansion of the fuel container effectively reduces the height of liquid fuel. As a result, the axial expansion of the fuel and the radial expansion of the fuel container are directly coupled in the SLFFR. Therefore, the computer codes developed for the conventional fast reactor safety analysis such as SAS4A/SASSYS-1 (Cahalan and Wei, 1990; Cahalan et al., 1994) cannot be used directly for the safety analysis of SLFFR. To investigate the transient behaviors of the SLFFR during the postulated accident scenarios, a multi-channel safety analysis code MUSA was developed with the thermal-fluidic and reactivity feedback models tailored to the unconventional design features of the SLFFR core.

The purpose of this paper is to describe the multi-channel safety analysis code MUSA and to present the passive safety characteristics of the SLFFR-1000 loop plant by performing transient analyses for various unprotected accident scenarios. Unprotected accident sequences assume multiple equipment failures, failures of safety grade protection and cooling systems, and no 
operator actions. These sequences are extreme tests of the SLFFR to provide inherent selfprotection against the consequences of the most severe accident initiators. Specifically, three beyond-design-basis accidents (BDBAs) of primary importance for passive safety were analyzed: unprotected transient over power (UTOP), unprotected loss of flow (ULOF) and unprotected loss of heat sink (ULOHS).

This paper is organized as follows. Section 2 describes the computational models of the MUSA code. Section 3 provides preliminary verification test results of MUSA against the SAS4A/SASSYS-1 code. The MUSA computational models of the SLFFR core and primary heat transport system are described in Section 4. Section 5 discusses the transient analysis results for UTOP, ULOF and ULOHS. Section 6 summarizes the key conclusions of the safety assessment of the SLFFR.

\section{Description of MUSA Models}

\subsection{General description and overall solution scheme}

MUSA solves the coupled neutronics and thermal-fluidic problems under steady state or transient conditions. Modular techniques are used in the MUSA code for the convenience of future expansion and update. The overall code structure and data flow are shown in Fig. 1. The thermal-fluidic behavior of the core is described by representing the core with one-dimensional parallel channels. The primary heat transport system is modeled by connecting compressible volumes by liquid segments. A point kinetics model with six delayed neutron groups is used to represent the power transients. The decay heat is calculated using the ANS decay heat standards ANSI/ANS-5.1 (ANS Standards Committee Working Group, 2005). The reactivity feedback is estimated by combining the temperature and density variations of liquid fuel, structural material and sodium coolant with the corresponding axial distributions of reactivity worth in each individual thermal-fluidic channel.

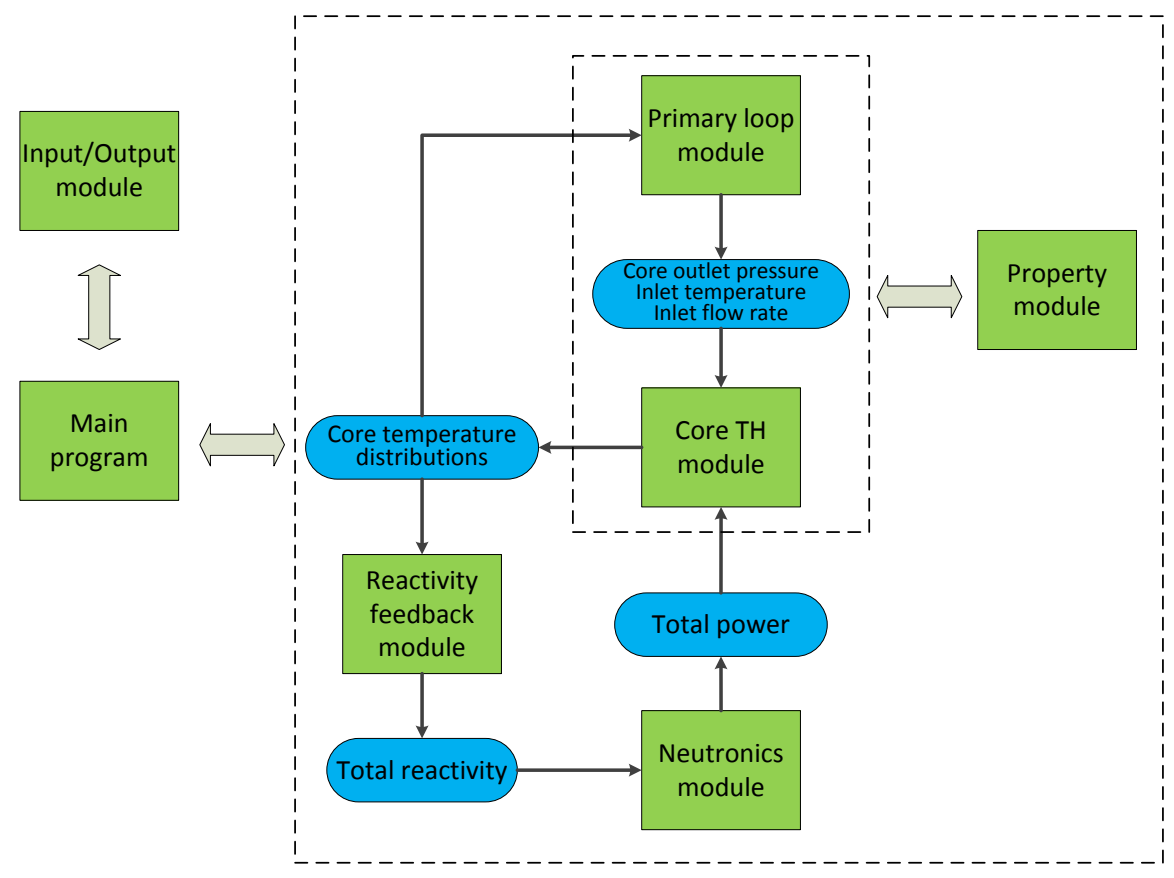

Fig. 1. Major Structure and Data Flows of the MUSA Code 
A transient calculation starts with determining the steady-state initial conditions for a given steady state power distribution. By solving the steady-state thermal-fluidic equations, the channel temperature distributions are determined first. The resulting axial distributions of the coolant, structure and fuel temperatures for each core channel are used as the base temperatures for the reactivity feedbacks. The temperatures and pressures in the inlet and outlet coolant plenums are also obtained from the core steady-state solution. The temperatures of all elements and compressible volumes in the hot side of the primary loop are set to the coolant temperature in the outlet plenum, and the temperatures of the components in the cold side of the primary loop are set to the inlet plenum temperature. After the primary loop temperatures are set, the pressure drops through all the components are calculated, and the pump head is calculated to achieve a pressure balance. In the current version of MUSA, the intermediate heat transport loops and steam generators are not modeled explicitly, and the heat removal rate or temperature of the intermediate heat exchanger (IHX) is specified as a boundary condition. The average temperature of the primary side of the IHX is obtained by averaging the inlet and outlet temperatures of the primary side of the IHX.

Four levels of time intervals are defined for transient analysis. The reactivity feedbacks are obtained in the main time step, which is specified by an input parameter. The primary-loop time step is a sub-step of the main step, which can either be provided as an input parameter or determined dynamically to satisfy the Courant-Friedrichs-Levy (CFL) stability condition (Courant et al., 1967) for the coolant flow in the core channel. The heat transfer calculation from fuel to coolant shares the same time step with the primary loop. The point kinetic time step is a sub-step of the primary-loop time step given by an input value. The last level of the time step is the editing time step for the output of the results, which is also a fixed input parameter.

\subsection{Power production models}

The transient behavior of power production is approximately predicted by a point reactor model. It is assumed that the initial flux shape remains constant, and the local power production is determined by the product of the dimensionless, normalized power amplitude and the initial power distribution. The time-dependent power amplitude is expressed as the sum of the direct fission component, and the decay heat from fission and capture products. The direct fission power component is described by the point kinetics equations with six delayed neutron groups as follows:

$$
\begin{aligned}
& \frac{d p(t)}{d t}=\frac{\rho(t)-\beta}{\Lambda} p(t)+\frac{1}{\Lambda} \sum_{i=1}^{6} \lambda_{i} \zeta_{i}(t) \\
& \frac{d \zeta_{i}(t)}{d t}=\beta_{i} p(t)-\lambda_{i} \zeta_{i}(t), \quad(i=1, \cdots, 6)
\end{aligned}
$$

where $p(t)$ is the fission power amplitude relative to the initial power level, $\zeta_{i}(t)$ is the reduced delayed neutron precursor concentration of group $i$ (Ott and Neuhold, 1985), $\rho(t)$ is the timedependent reactivity, $\Lambda$ is the neutron generation time, and $\beta_{i}$ and $\lambda_{i}$ are the delayed neutron fraction and the decay constant for the delayed neutron precursor in group $i$, respectively. In the MUSA code, the point kinetics equations are discretized using the $\theta$-method (Smith, 1979; Vota, 1969), which is a variable time integration scheme. This method permits the resulting difference 
equations to range from fully explicit when $\theta=0$ to fully implicit when $\theta=1$. The CrankNicolson scheme is obtained when $\theta=0.5$.

The decay heat is calculated using the ANS decay heat standards ANSI/ANS-5.1 (ANS Standards Committee Working Group, 2005), where the decay heat at time $t$ after one fission pulse is represented as

$k(t)=\sum_{i=1}^{23} \alpha_{i} e^{-\lambda_{i} t}$

where $\alpha_{i}$ and $\lambda_{i}$ are fitting parameters. The decay heat function is fissionable isotope dependent and the decay heat functions for $\mathrm{U}-235, \mathrm{U}-238$ and $\mathrm{Pu}-239$ are provided in the reference.

\subsection{Reactivity feedback models}

The reactivity feedback is estimated by combining the temperature and density variations of fuel, structural material and sodium coolant with the corresponding axial distributions of reactivity worth in each individual thermal-fluidic channel. The total reactivity is calculated as the sum of the components shown in Table 1, which is a function of time:

$\rho(t)=\rho_{e x t}(t)+\delta \rho_{D}(t)+\delta \rho_{a x}(t)+\delta \rho_{r e}(t)+\delta \rho_{N a}(t)+\delta \rho_{C R D L}(t)+\delta \rho_{G E M}(t)$

\section{Table 1}

Feedback Reactivity Components in MUSA Model

\begin{tabular}{ll}
\hline symbol & Reactivity component \\
\hline$\rho_{e x t}$ & User-defined external reactivity \\
$\delta \rho_{D}$ & Fuel Doppler feedback reactivity \\
$\delta \rho_{a x}$ & Reactivity feedback due to axial expansion of fuel and coolant tube \\
$\delta \rho_{r e}$ & Reactivity feedback due to radial expansion of fuel container \\
$\delta \rho_{N a}$ & Coolant density or voiding feedback reactivity \\
$\delta \rho_{C R D L}$ & Reactivity induced by control rod drive line thermal expansion \\
$\delta \rho_{\text {GEM }}$ & Reactivity induced by gas expansion in GEMs \\
\hline
\end{tabular}

The fuel Doppler reactivity change $\delta \rho_{D}^{i}(z)$ due to the fuel temperature perturbation at an axial location $z$ in a thermal-fluidic channel $i$ is estimated with the usual $1 / T$ dependence as

$$
\frac{d}{d T_{f}^{i}(z)} \delta \rho_{D}^{i}(z)=\frac{\alpha_{D}^{i}(z)}{T_{f}^{i}(z)}
$$

where $T_{f}^{i}(z)$ is the local fuel temperature, and $\alpha_{D}^{i}(z)$ is the local Doppler constant, that is, the inverse proportional constant of the reactivity change due to the temperature change in a unit length of fuel at axial location $z$ of channel $i$. The axial distribution of the local Doppler constant can be calculated using a generalized perturbation theory code such as VARI3D (Smith et al., 2013). Two sets of Doppler constant distribution need to be specified: one is for the normal, coolant-in (flooded) condition and the other is for the coolant-out (voided), accident 
condition. Using the specified Doppler constants, the Doppler reactivity feedback due to the fuel temperature change at axial position $z$ at time $t$ is obtained by integrating Eq. (5) from the steady-state temperature to the temperature at time $t$ as

$\delta \rho_{D}^{i}(z, t)=\alpha_{D}^{i}(z) \ln \frac{T_{f}^{i}(z, t)}{T_{f}^{i}(z, 0)}$

Using the Doppler feedback distribution in Eq. (6), the total fuel Doppler feedback reactivity is calculated as

$\delta \rho_{D}(t)=\sum_{i} \int_{0}^{H} \delta \rho_{D}^{i}(z, t) d z$

The reactivity resulting from core dimension changes is the most important feedback mechanism of fast reactors. In addition, the axial expansion of the fuel and the radial expansion of the fuel container are directly coupled in the SLFFR, since the radial expansion of the fuel container effectively reduces the height of liquid fuel. Consequently, the axial meshes of expanded fuel should be determined by simultaneously considering the axial fuel expansion and the radial expansion of the fuel container. For each axial node $k$ in a channel $i$, the axial expansions of fuel are calculated first as illustrated in Fig. 2. Using the original mesh size $\Delta z_{i, k}^{0}=z_{i, k}-z_{i, k-1}$, the corresponding mesh size for expanded fuel at $t=t_{n}$ is determined as

$\Delta z_{a x, i, k}^{n}=\Delta z_{i, k}^{0}\left[1+\alpha_{l, f} \Delta T_{f, i, k}^{n}\right]$

where $\alpha_{l, f}$ is the linear thermal expansion coefficient of fuel, and $\Delta T_{f, i, k}^{n}$ is the increase in the average fuel temperature of the axial mesh $k$ of channel $i$ at time $t=t_{n}$ from that at $t=0$, which is obtained from the thermal-fluidic module.

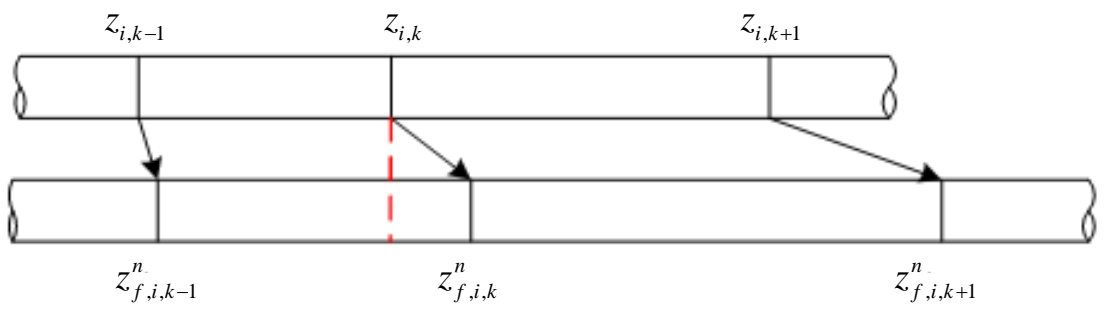

Fig. 2. Axial Meshes of Original and Expanded Fuel

The increased radius of the fuel container at axial mesh $k$ at $t=t_{n}$ can be simply calculated as $R_{w, k}^{n}=R_{w, k}\left(1+\alpha_{l, w} \Delta T_{w, k}^{n}\right)$

where $\alpha_{l, w}$ is the linear thermal expansion coefficient of fuel container and $\Delta T_{w, k}^{n}$ is the increase in the average fuel container temperature of the axial mesh $k$ at time $t=t_{n}$ from that at $t=0$, which is obtained from the thermal-fluidic module. Since the liquid fuel volume is preserved for the container expansion, the fuel mesh interval is reduced by

$\delta \Delta z_{r d, i, k}^{n}=\Delta z_{i, k}^{0}\left[\left(1+\alpha_{l, w} \Delta T_{w, k}^{n}\right)^{-2}-1\right]$ 
By combining the axial and radial expansions in Eq. (8) and Eq. (10), the resulting axial mesh size of fuel can be obtained as

$$
\begin{aligned}
\Delta z_{f, i, k}^{n} & =\Delta z_{a x, i, k}^{n}+\Delta z_{r d, i, k}^{n}=\Delta z_{i, k}^{0}\left[\alpha_{l, f} \Delta T_{f, i, k}^{n}+\left(1+\alpha_{l, w} \Delta T_{w, k}^{n}\right)^{-2}\right] \\
& \approx \Delta z_{i, k}^{0}\left[1+\alpha_{l, f} \Delta T_{f, i, k}^{n}-2 \alpha_{l, w} \Delta T_{w, k}^{n}\right]
\end{aligned}
$$

Using these mesh sizes, the upper boundary of mesh $k$ can be determined as

$$
z_{f, i, k}^{n}=\sum_{j=1}^{k} \Delta z_{f, i, j}^{n}=\sum_{j=1}^{k} \Delta z_{i, j}^{0}\left[\alpha_{l, f} \Delta T_{f, i, j}^{n}+\left(1+\alpha_{l, w} \Delta T_{w, j}^{n}\right)^{-2}\right]
$$

Denoting the reactivity worth per unit mass of fuel in the axial mesh $k$ of channel $i$ by $\rho_{w, f}^{i, k}$, the reactivity change due to the mesh boundary changes of axial mesh $k$ of channel $i$ caused by the axial fuel expansion and the radial expansion of the fuel container can be estimated as

$$
\delta \rho_{f, i, k}^{n}=m_{f, i, k}\left[\rho_{w, f}^{i, k} \frac{z_{i, k}-z_{f, i, k-1}^{n}}{z_{f, i, k}^{n}-z_{f, i, k-1}^{n}}+\rho_{w, f}^{i, k+1} \frac{z_{f, i, k}^{n}-z_{i, k}}{z_{f, i, k}^{n}-z_{f, i, k-1}^{n}}-\rho_{w, f}^{i, k}\right]
$$

where $m_{f, i, k}$ is the fuel mass in the axial mesh $k$ of channel $i$. The material worth in the region beyond the nominal fuel height is determined by linear extrapolation of the calculated worth. The total reactivity change due to fuel axial expansion can be determined by summing up the contributions of individual meshes in Eq. (13) as

$$
\delta \rho_{f}^{n}=\sum_{i} \sum_{k=1}^{K} \delta \rho_{f, k}^{n}
$$

The reactivity feedback caused by axial expansion of coolant tubes is calculated using a similar expression to Eq. (13). That is, using the perturbed mesh boundaries $z_{w, i, k}^{n}$ and the reactivity worth per unit mass of coolant tube $\rho_{w, w}^{i, k}$, the reactivity change due to the mesh boundary changes of axial mesh $k$ of channel $i$ from the axial expansion of coolant tubes is determined as

$$
\delta \rho_{w, i, k}^{n}=m_{w, i, k}\left[\rho_{w, w}^{i, k} \frac{z_{i, k}-z_{w, i, k-1}^{n}}{z_{w, i, k}^{n}-z_{w, i, k-1}^{n}}+\rho_{w, w}^{i, k+1} \frac{z_{w, i, k}^{n}-z_{i, k}}{z_{w, i, k}^{n}-z_{w, i, k-1}^{n}}-\rho_{w, w}^{i, k}\right]
$$

The total reactivity due to axial expansion of coolant tubes is obtained by summing up the individual mesh contributions in Eq. (15).

Reactivity feedback effects from either single-phase coolant density changes or two-phase coolant boiling are calculated using the local coolant density changes. Sodium void worth distributions are also the reactivity change per unit mass, but are in terms of the amount of mass reduced (voided) rather than the amount of mass present. The reactivity feedback from coolant density and voiding changes is calculated from

$$
\delta \rho_{N a, i}^{n}=\sum_{k=1}^{K} \rho_{w, N a}^{i, k} \delta v_{N a, i, k}^{n}=\sum_{k=1}^{K} \rho_{w, N a}^{i, k}\left(-\delta m_{N a, i, k}^{n}\right)
$$


where $\rho_{w, N a}^{i, k}$ is the coolant void worth in axial mesh $k$ of channel $i$ in $\$ / \mathrm{g}$, and $\delta v_{N a, i, k}^{n}$ is the amount of coolant voided in axial mesh $k$ of channel $i$ at $t=t_{n}$, that is, $\delta v_{N a, i, k}^{n}=-\delta m_{N a, i, k}^{n}$ with $\delta m_{N a, i, k}^{n}$ being the coolant mass increase.

\subsection{Core thermal-fluidic models}

The thermal-fluidic behavior of the core is described with independent parallel channels connected at the inlet and the outlet. The inlet coolant flow is distributed among these channels to satisfy the equal pressure drop boundary conditions. Once the flow rates to individual channels are determined, the axial temperature distributions of coolant, coolant tube, and fuel are determined by solving the single-channel thermal-fluidic equations with known axial power distribution and outlet pressure as well as the flow rate and temperature of inlet coolant.

\subsubsection{Single channel thermal-fluidic model}

The coolant channel configuration of the SLFFR is topologically inverted relative to that of the conventional solid fuel pin as compared in Fig. 2. The MUSA code models both channel configurations by solving the same set of governing equations with different boundary conditions and heat source locations.

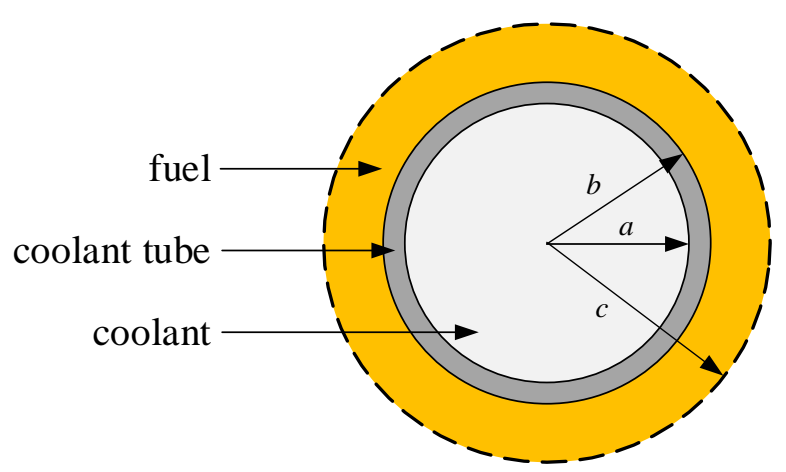

(a) SLFFR

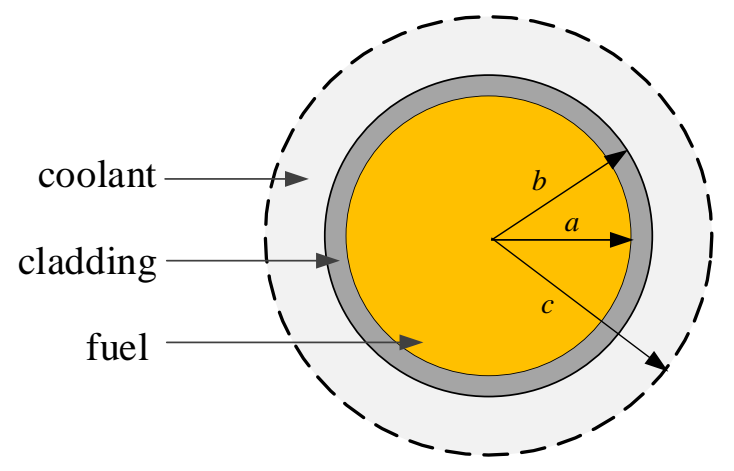

(b) Conventional solid fuel pin

Fig. 2. Single Channel Thermal-Fluidic Models for SLFFR and Conventional Solid Fuel Pin

Neglecting the heat conduction and shear forces due to velocity gradients in the fluid at open portions of the surface area, the mass, momentum and energy balance equations for onedimensional flow in a vertical coolant tube can be written as (Todreas and Kazimi, 2012)

$$
\begin{aligned}
& \frac{\partial}{\partial t} \rho(t, z)+\frac{\partial}{\partial z}[\rho(t, z) v(t, z)]=0 \\
& \frac{\partial}{\partial t}[\rho(t, z) v(t, z)]+\frac{\partial}{\partial z}\left[\rho(t, z) v^{2}(t, z)\right]=-\frac{\partial}{\partial z} P(t, z)-\rho(t, z) g-\frac{f \rho(t, z)|v(t, z)| v(t, z)}{2 D_{h}} \\
& \rho(t, z) c_{p}\left[\frac{\partial}{\partial t} T_{c}(t, z)+v(t, z) \frac{\partial}{\partial z} T_{c}(t, z)\right]=\frac{P_{h}}{A} q^{\prime \prime}(t, z)
\end{aligned}
$$


where $\rho, v, T_{c}$ and $P$ are the density, velocity, temperature, and pressure of coolant, respectively, and $q^{\prime \prime}$ is the heat flux at the coolant side surface of the coolant tube (or cladding). The parameters $D_{h}, P_{h}$, and $A$ represent the hydraulic diameter, the wetted perimeter and the flow area of the coolant channel, respectively, and $g$ is the gravitational acceleration. The parameter $c_{p}$ is the specific heat of sodium coolant and $f$ is the turbulent friction factor that is determined from Blasius relation or McAdams relation (Todreas and Kazimi, 2012) depending on the Reynolds number of flow

$$
f= \begin{cases}0.316 \mathrm{Re}^{-0.25}, & \operatorname{Re}<30,000 \text { (Blasius relation) } \\ 0.184 \mathrm{Re}^{-0.2}, & 30,000<\operatorname{Re}<10^{6} \quad \text { (McAdams relation) }\end{cases}
$$

Neglecting the axial conduction, the heat conduction in the fuel and the coolant tube (or cladding) can be represented by the following heat conduction equations:

$$
\begin{aligned}
& \rho_{f} c_{p, f} \frac{\partial}{\partial t} T_{f}(r, z, t)=q^{\prime \prime \prime}(r, z, t)+\frac{1}{r} \frac{\partial}{\partial r}\left[r k_{f} \frac{\partial T_{f}(r, z, t)}{\partial r}\right] \\
& \rho_{w} c_{p, w} \frac{\partial}{\partial t} T_{w}(r, z, t)=\frac{1}{r} \frac{\partial}{\partial r}\left[r k_{w} \frac{\partial T_{w}(r, z, t)}{\partial r}\right]
\end{aligned}
$$

where $T_{f}$ and $T_{w}$ are the fuel and coolant tube (or cladding) temperatures, respectively, and $q^{\prime \prime \prime}$ is the volumetric heat source in the fuel. The density, specific heat, and heat conductivity of fuel and coolant tube (or cladding) are denoted by $\rho, c_{p}$, and $k$, respectively, with a subscript $f$ for fuel and $w$ for coolant tube (or cladding).

The heat conduction equations of fuel and coolant tube (or cladding) are coupled through the interface conditions at the coolant tube outer wall (see Fig. 2 (a)):

$$
\left\{\begin{array}{l}
T_{f}(b, z, t)=T_{w}(b, z, t) \\
\left.k_{f} \frac{\partial T_{f}(r, z, t)}{\partial r}\right|_{r=b}=\left.k_{w} \frac{\partial T_{w}(r, z, t)}{\partial r}\right|_{r=b}
\end{array}\right.
$$

or at the cladding inner wall (see Fig. 2(b)):

$$
\left\{\begin{array}{l}
T_{f}(a, z, t)=T_{w}(a, z, t) \\
\left.k_{f} \frac{\partial T_{f}(r, z, t)}{\partial r}\right|_{r=a}=\left.k_{w} \frac{\partial T_{w}(r, z, t)}{\partial r}\right|_{r=a}
\end{array}\right.
$$

The other boundary condition for the heat conduction in the fuel is given by the symmetry condition at the outer boundary of the liquid fuel ring (see Fig. 2 (a)):

$$
\left.\frac{\partial T_{f}(r, z, t)}{\partial r}\right|_{r=c}=0
$$

or at the centerline of the fuel pin (see Fig. 2(b)): 
$\left.\frac{\partial T_{f}(r, z, t)}{\partial r}\right|_{r=0}=0$

The heat conduction equation for the coolant tube (or cladding) in Eq. (22) is coupled with the coolant energy equation in Eq. (19), through the Newton's law for heat convection at the coolant tube inner wall (see Fig. 2 (a)):

$\left.k_{w} \frac{\partial T_{w}(r, z, t)}{\partial r}\right|_{r=a}=h_{w}\left[T_{w}(a, z, t)-T_{c}(z, t)\right]$

or at the cladding outer surface (see Fig. 2 (b)):

$\left.k_{w} \frac{\partial T_{w}(r, z, t)}{\partial r}\right|_{r=b}=h_{w}\left[T_{w}(b, z, t)-T_{c}(z, t)\right]$

where $h_{w}$ is the convective heat transfer coefficient determined by the thermal conductivity of the coolant, the hydraulic diameter of the coolant channel $D_{h}$, and the Nusselt number $\mathrm{Nu}$. The Nusselt number characterizes the physical properties of the coolant and the dynamical characteristics of its flow. It is normally provided by empirical correlations. For this work, the Lyon-Martinelli correlation (Lyon, 1951) is used

$\mathrm{Nu}=7.0+0.025 \mathrm{Pe}^{0.8}$

where Pe is the Peclet number.

\subsubsection{Flow split}

The total coolant flow is distributed among multiple parallel channels that have common inlet and outlet plena, and thus it splits into the channels to yield the equal pressure drop across each channel. For a given mass flux $G_{i}$ of channel $i$, the pressure drop $\Delta P_{i}$ across the channel $i$ can be determined by solving the single-channel thermal-hydraulics problem. Therefore, denoting the pressure drop as a function of the mass flux as $\Delta P_{i}\left(G_{i}\right)$, the system of governing equations for unknown mass fluxes for $I$ parallel channels can be written as the following system of nonlinear equations:

$\Delta P_{1}\left(G_{1}\right)=\Delta P_{2}\left(G_{2}\right)=\cdots=\Delta P_{I}\left(G_{I}\right)=\overline{\Delta P}$

$\sum_{i=1}^{I} N_{i} A_{i} G_{i}=W_{T}$

where $N_{i}$ and $A_{i}$ are the number of coolant tubes and flow area of channel $i$, and $W_{T}$ is the total flow rate.

The system of nonlinear equations given in Eq. (30) and Eq. (31) can be solved iteratively using the Newton-Raphson method. The derivatives required in the Newton-Raphson method can be estimated by the finite difference approximation based on the single channel solutions for given mass fluxes. For transient conditions, the previous time step flow rates are used as the initial guess, which generally makes the flow split iteration converge in a couple of iterations. 


\subsection{Numerical methods for the core thermal-fluidics}

The control volume approach of RELAP5 (RELAP5 Development Team, 2001) is adopted for the spatial discretization of the flow equations. The heat conduction equations in fuel and coolant tube (or cladding) are spatially discretized with the mesh-centered finite-difference scheme. The numbers of axial and radial meshes in the problem domain are user-supplied parameters. The mesh structure is shown in Fig. 3. A semi-implicit scheme is used for the temporal discretization of flow equations, while a fully implicit scheme is used for discretizing the heat conduction equations.

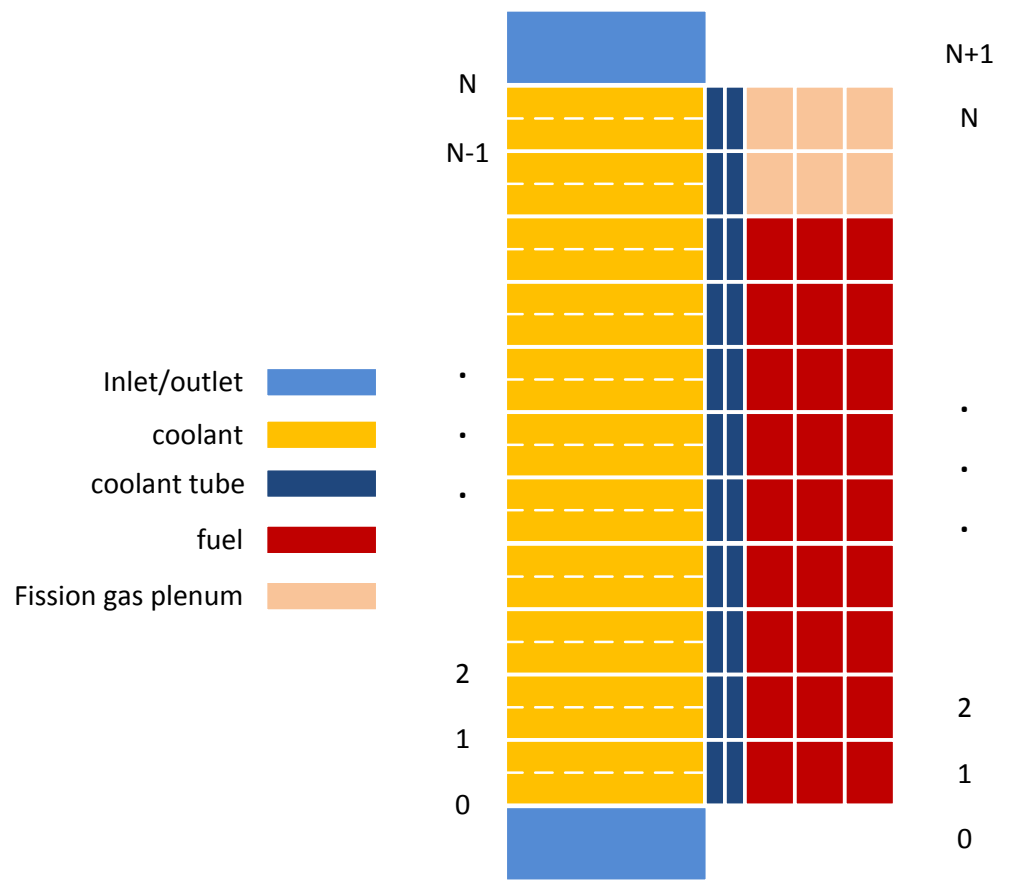

Fig. 3. Mesh Structure for Heat Conduction Calculation in Fuel, Coolant Tube and Coolant

\subsubsection{Numerical method for flow equations}

In the control volume approach adopted in this study, the problem domain is divided into computational cells as illustrated in Fig. 3, where the regions bounded by horizontal solid lines denote the main computational cells. Each grid point is placed at the geometric center of each cell. Field variables such as density, pressure, and enthalpy are defined at these grid points, and the flow variables such as velocity component and mass flux are defined on cell faces (or junctions). The main control volumes for mass and energy balances are defined by these cells. The momentum control volume is displaced from the main control volume in the velocity direction, extending from grid points to grid points and encompassing the cell face upon which the velocity component is defined. The finite difference equations are derived by integrating the mass, momentum, and energy equations over the control volumes under the assumption that the values at the center of each control volume prevail over the control volume.

The spatially discretized governing equations provide a system of nonlinear ordinary differential equations for the cell-averaged temperatures, cell-center pressures, and cell-face velocities. By applying a fully explicit temporal difference scheme, these equations can be converted into a system of linear equations. However, for an incompressible flow, the fully 
explicit scheme does not yield an equation to update the coolant pressure. On the other hand, the fully implicit scheme yields a system of nonlinear equations, which requires a more complicated solution scheme. As a compromise, a semi-implicit scheme of the RELAP5 code (RELAP5 Development Team, 2001) has been adopted.

The semi-implicit numerical solution scheme is based on replacing the system of differential equations with a system of finite difference equations partially implicit in time. The implicit terms are formulated to be linear in the dependent variables at new time. Implicitness is selected such that the field equations can be reduced to a single difference equation per coolant control volume or mesh cell in terms of the hydrodynamic pressure. This results in a system of linear equations for the time advanced pressures. Since the coefficient matrix is a tri-diagonal matrix, this system of linear equations can easily be solved by the forward elimination and backward substitution algorithm. Substitution of the new time pressures into the momentum balance equation yields the new time velocities. Using the new time velocities, the new time densities and temperatures can be obtained from the mass and energy balance equations, respectively.

\subsubsection{Numerical method for heat conduction equations}

The fuel and coolant tube are divided into computational cells as illustrated in Fig. 3. Each grid point is placed at the geometric center of each cell. The temperatures are defined at these grid points. The finite difference equations are derived by integrating the heat conduction equation over the cell volumes under the assumption that the values at the center of each cell prevail over the cell volume. Since the heat conduction equations for the fuel and the coolant tube in Eq. (21) and Eq. (22) are identical except for the heat conductivity and the heat generation rate, both equations can be solved simultaneously using the same numerical scheme.

Using the fully implicit temporal difference scheme for temperature and the previous time heat source, the spatially discretized finite difference equations form a system of equations for the advanced time temperatures of fuel and coolant tube. The coolant temperature are determined by solving the coolant flow equations, and the volumetric heat sources are calculated using the initial power distribution and the power amplitude determined by solving the point kinetics equations. With known source terms, these equations form a system of nonlinear equations since the coefficients depend on the unknown temperatures through the temperature dependent material properties.

This system of nonlinear equations can be solved iteratively. Initially the coefficients are estimated using the previous time temperatures. For known coefficients, the system of equations becomes a system of linear equations. This is a tri-diagonal system, and hence it can easily be solved by the forward elimination and backward substitution algorithm used for solving the system of coolant pressure equations. Using the updated temperatures, the temperaturedependent coefficients are updated. This iteration between temperatures and material properties continues until the successive temperatures converge within a specified limit.

\subsection{Primary loop model}

For the primary loop thermal-fluidic analysis, the mass, momentum, and energy balance equations of the primary loop are solved simultaneously. For simplicity, the energy equations for individual components (upper plenum, lower plenum, IHX, etc.) are solved first using lumped parameter models, and then the solutions are coupled with the mass and momentum equations though updated mass flow rates. 


\subsubsection{Energy balance}

In the lumped parameter model, each component is represented by a single node with an average coolant temperature. Assuming that the structural materials are at the thermal equilibrium with the sodium coolant in each component, the energy balance equations can be written as

$C_{i} \frac{d \bar{T}_{i}}{d t}=\dot{m}_{\text {in }}^{i} c_{p} T_{\text {in }}^{i}-\dot{m}_{\text {out }} c_{p} T_{\text {out }}^{i}-\dot{Q}_{i}$

where $C_{i}$ and $\dot{Q}_{i}$ are the heat capacities and heat removal rate of the component $i$, respectively. $T_{\text {in }}^{i}, T_{\text {out }}^{i}$ and $\bar{T}_{i}$ are the inlet, outlet and average temperatures of the component $i$, respectively. $\dot{m}_{i n}^{i}$ and $\dot{m}_{\text {out }}$ are the inlet and outlet coolant mass flow rates of the component $i$, respectively. $c_{p}$ is the specific heat of sodium at the corresponding temperature. The resulting set of ordinary differential equations is solved using the upwind scheme for spatial differencing and the explicit scheme for time differencing.

\subsubsection{Fluidic model}

The compressible volumes and liquid segments of the SAS4A/SASSYS- 1 code were adopted for the primary loop fluidic calculations (Fanning, et al., 2012). In this approach, the primary heat transport system (PHTS) is modeled by connecting compressible volumes by liquid segments. Compressible volumes are used to represent the inlet plenum, outlet plenum with cover gas, pool, etc. and are characterized by pressure, volume, mass, and temperature. They can accumulate liquid or gas by compressing the cover gas or the liquid, and the pressures in the compressible volumes drive the flows through the liquid and gas segments. Liquid segments are one-dimensional flow paths between two control volumes, and each liquid segment can contain one or more elements such as core assembly channels, shell and tube sides of an intermediate heat exchanger, shell and tube sides of a heat exchanger of the direct reactor auxiliary cooling system (DRACS), pipes, etc. Two simplified primary loop fluidic models are implemented in the MUSA code. The pool-type model consists three compressible volumes (CVs) connected by three liquid segments (LSs) while the loop-type model considered two compressible volumes connected by two liquid segments as shown in Fig. 4.

The momentum equation for a single-phase, incompressible one-dimensional flow can be written as

$$
\frac{1}{A} \frac{\partial w}{\partial t}+\frac{1}{A^{2}} \frac{\partial}{\partial z}\left(\frac{w^{2}}{\rho}\right)=-\frac{\partial P}{\partial z}-\left(\frac{\partial P}{\partial z}\right)_{\text {loss }}
$$

where $w$ is the mass flow rate. By integrating Eq. (33) over a segment containing several elements, the basic equation for the flow in segment $i$ can be obtained as

$$
\sum_{k \in i} \frac{L_{k}}{A_{k}} \frac{\partial w_{i}}{\partial t}=P_{i, \text { in }}(t)-P_{i, \text { out }}(t)-\Delta P_{i, f r}\left[w_{i}(t)\right]-\Delta P_{i, \text { form }}\left[w_{i}(t)\right]-\Delta P_{i, g r}(t)+\Delta P_{i, p}
$$




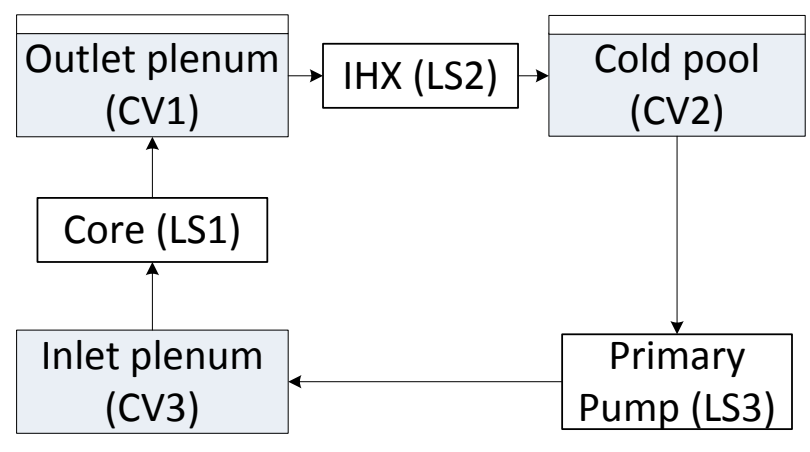

(a) Pool-type

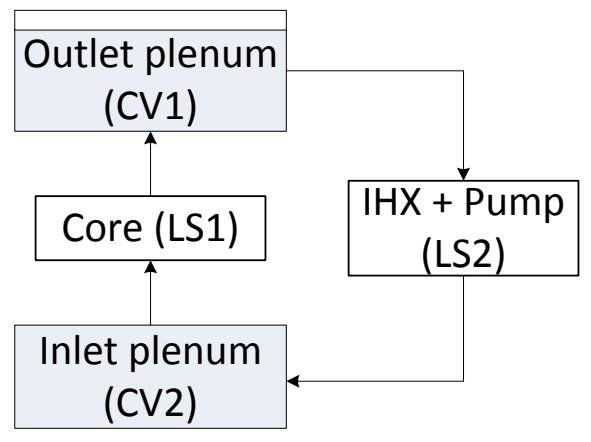

(b) Loop-type

Fig. 4. Compressible Volumes and Liquid Segments of Pool-type and Loop-type PHTS

where $A_{k}$ and $L_{k}$ are the flow area and length of element $k$, respectively. The term $P_{i, i n}$ is the pressure at the inlet to segment $i$, which is equal to the pressure $P_{j i}$ in the compressible volume $j i$ at the inlet to segment $i$, and the term $P_{i, o u t}$ is the pressure at the outlet of segment $i$, which is equal to the pressure $P_{j o}$ in the compressible volume $j o$ at the outlet of segment $i$. The pressure drop $\Delta P_{i, f r}$ is the sum of the frictional pressure losses for all the elements in segment $i$, the pressure drop $\Delta P_{i, f o r m}$ is the total form pressure loss due to the valves, fittings, orifices, bends, etc. in segment $i$. The term $\Delta P_{i, g r}$ is the gravity-head pressure drop, and the term $\Delta P_{i, p}$ is the pumphead pressure increase from all of the pumps in segment $i$. The pump head and torque of a centrifugal pump are functions of pump speed and flow rate, but in this study, a simple model was used by specifying the pump head as a function of time as

$\Delta P_{p}=\Delta P_{p 0} h(t)$

where $\Delta P_{p 0}$ is the reference pump head with $h(0)=1$.

The skin friction and form pressure losses are proportional to the square of the mass flow rate, and hence Eq. (34) can be written as

$\sum_{k \in i} \frac{L_{k}}{A_{k}} \frac{\partial w_{i}}{\partial t}=f\left(w_{i}, t\right)$

By applying a fully implicit differencing scheme, Eq. (36) can be written in finite difference form as

$\sum_{k \in i} \frac{L_{k}}{A_{k}} \frac{\Delta w_{i}(t)}{\Delta t}=f\left[w_{i}(t+\Delta t), t+\Delta t\right]$

where $\Delta w_{i}(t)=w_{i}(t+\Delta t)-w_{i}(t)$. The right hand side of Eq. (37) can be linearized around $w_{i}(t)$ as

$f\left[w_{i}(t+\Delta t), t+\Delta t\right]=f\left[w_{i}(t), t\right]+\frac{\partial f}{\partial w_{i}} \Delta w_{i}(t)+\frac{\partial f}{\partial t} \Delta t$ 
By inserting Eq. (38) into Eq. (37) and using the right hand side of Eq. (34) for $f\left(w_{i}, t\right)$, the flow rate change $\Delta w_{i}$ can be obtained in the form of

$$
\Delta w_{i}(t)=\frac{a_{i 1}+a_{i 2}+\Delta t\left(\Delta P_{j i}-\Delta P_{j o}\right)}{a_{i 0}-a_{i 3}}
$$

where the coefficient $a_{i 0}$ is the summation of the ratios of flow length to area of all the elements in segment $i$. The coefficients $a_{i 1}$ to $a_{i 3}$ are the three terms of the right hand side of Eq. (38) multiplied by the time step. By taking an average of the flow rates at the beginning and at the end of the time step, the average mass flow rate in a liquid segment during a time step can be obtained as

$$
\bar{w}_{i}=w_{i}(t)+\frac{a_{i 1}+a_{i 2}+\Delta t\left(\Delta P_{j i}-\Delta P_{j o}\right)}{2\left(a_{i 0}-a_{i 3}\right)}
$$

By assuming that the pressure in a compressible volume varies linearly with changes in the mass or temperature of the liquid, the pressure change $\Delta P_{j}$ in the compressible volume $j$ during a time step can be obtained as

$$
\Delta P_{j}=b_{j 0}+b_{j 1}\left[\sum_{i} \bar{w}_{i, \text { in }}-\sum_{i} \bar{w}_{i, \text { out }}\right]+b_{j 2}\left[\sum_{i} \bar{w}_{i, \text { in }} T_{j, \text { in }}^{i}-\sum_{i} \bar{w}_{i, \text { out }} T_{j, \text { out }}\right]
$$

where $\bar{w}_{i, i n}$ is the average mass flow rate of segment $i$ that flows into a compressible volume $j$ and $\bar{w}_{i, \text { out }}$ is the average mass flow rate of segment $i$ that flows out from a compressible volume $j$. The temperature $T_{j, i n}^{i}$ is the temperature of the flow incoming to a compressible volume $j$ through segment $i$, which is equal to the outlet temperature $T_{i, \text { out }}$ of segment $i$, and $T_{j, \text { out }}$ is the outlet temperature of a compressible volume $j$, which is equal to the inlet temperature of segment $i$. The coefficients $b_{j 1}$ and $b_{j 2}$ include the time-step size and are computed for each type of compressible volume. The remaining term $b_{j 0}$ also contains the time step size, and it can be used to account for the effects of heat transfer to the compressible liquid from the compressible volume wall or from other components.

Equations (40) and (41) constitute a set of simultaneous equations for the average mass flow rates $\bar{w}_{i}$ of the liquid segments and the pressure changes $\Delta P_{j}$ in the compressible volumes during a time step. By solving this system of equations, the pressures in control volumes and the average mass flow rates in liquid segments can be obtained for each time step.

\section{Verification Tests of MUSA Code}

Before the safety analyses of SLFFR, verification tests of the MUSA code were performed by a code-to-code comparison with the well-validated safety analysis code SAS4A/SASSYS-1. The steady-state operating conditions and the ULOF accident scenario of the advanced burner test reactor (ABTR) were analyzed using the MUSA code, and the results were compared with the reference solutions obtained with the SAS4A/SASSYS-1 code system (Dunn, et al., 2006). 


\subsection{ABTR model description}

The ABTR is a metallic-fueled, sodium-cooled, pool-type reactor system designed at Argonne National Laboratory (Chang, et al., 2006). The thermal power rating is $250 \mathrm{MW}$. The inlet and outlet coolant temperatures are $355^{\circ} \mathrm{C}$ and $510{ }^{\circ} \mathrm{C}$, respectively. The thermal-fluidic behavior of the reactor core is analyzed with a multi-channel core model. The core assemblies are grouped into five flow regions, each of which is represented by an individual thermal-fluidic channel. As shown in Fig. 5, channels 1 and 3 represent the average assemblies in the inner and outer enrichment zones, respectively, while channel 2 represents the average of the mid-core fuel test assemblies. The fourth channel represents all of the non-fuel assemblies and the peak-power inner-core assembly with fresh fuel is represented by the fifth channel. The channel powers and flow rates are summarized in the Table 2. The coolant system thermal-fluidic model in the SAS4A/SASSYS-1 analysis represents the coolant flow and heat transfer in the primary and intermediate sodium systems, and in the emergency decay heat removal system, with a network of volumes and components connected by flow paths. In the MUSA simulation, the coolant system thermal-fluidic behavior is represented by the simplified loop-type PHTS model shown in Fig. 4 (a) since the intermediate loop model has not been incorporated in MUSA code.
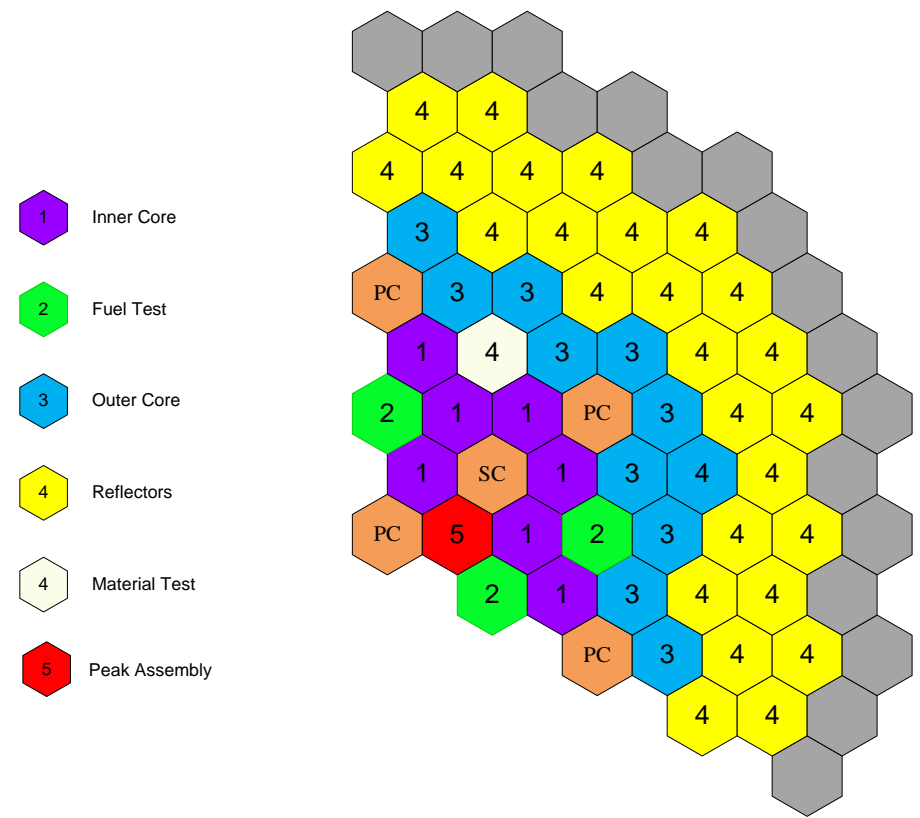

Table 2

Fig. 5. Channel Assignment for ABTR Core Thermal-fluidic Model

Assembly Power and Flow Rate for Channels

\begin{tabular}{llll}
\hline $\begin{array}{l}\text { Channel } \\
\text { No. }\end{array}$ & Assembly group & $\begin{array}{l}\text { Assembly power } \\
(\mathrm{MW})\end{array}$ & $\begin{array}{l}\text { Assembly flow } \\
\text { rate }(\mathrm{kg} / \mathrm{s})\end{array}$ \\
\hline 1 & Inner core & 5.59 & 27.30 \\
2 & Fuel test & 5.13 & 26.99 \\
3 & Outer core & 4.49 & 23.92 \\
4 & Reflector \& material test & 0.26 & 1.23 \\
5 & Peak assembly & 7.02 & 30.05 \\
\hline
\end{tabular}




\subsection{Comparison of the analysis results}

The verification of MUSA code was conducted in two steps. In the first step, the steady state (or null transient) solution obtained by the MUSA code was compared with reference solution calculated using SAS4A/SASSYS-1 codes. Table 3 compares the steady-state solutions of SAS4A/SASSYS-1 and MUSA for the mass flow rate, the coolant outlet temperature, the peak cladding mid-wall temperature, and the peak fuel centerline temperature in each thermal-fluidic channel. It can be seen that the MUSA results agree very well with the SAS4A/SASSYS-1 solutions. The channel flow rates show only small differences due to the differences in the friction factor correlations. The peak cladding and fuel temperatures as well as the coolant outlet temperatures of MUSA agree well with the reference solution. The maximum difference of around $2{ }^{\circ} \mathrm{C}$ is observed due to the small differences in the flow rates and in the convection heattransfer coefficient correlations.

Table 3

Steady-State Results Calculated by MUSA and SAS4A/SASSYS-1 Codes

\begin{tabular}{lrrrrr} 
& Inner core & Fuel test & Outer core & Reflectors & \multicolumn{1}{c}{$\begin{array}{l}\text { Peak } \\
\text { assembly }\end{array}$} \\
\hline Flow rate, kg/s & & & & & \\
SAS4A/SASSYS-1 & 27.30 & 26.99 & 23.92 & 1.23 & 30.05 \\
MUSA & 27.21 & 27.06 & 24.03 & 1.24 & 30.22 \\
Difference & 0.09 & -0.07 & -0.11 & -0.01 & -0.17 \\
Coolant outlet temperature, ${ }^{\circ} \mathrm{C}$ & 518.92 & 504.30 & 502.45 & 523.29 & 538.76 \\
SAS4A/SASSYS-1 & 518.95 & 503.33 & 501.19 & 522.30 & 537.31 \\
MUSA & -0.03 & 0.96 & 1.26 & 0.99 & 1.45 \\
Difference & 526.67 & 511.23 & 508.35 & 521.10 & 548.55 \\
Peak cladding mid-wall temperature, ${ }^{\circ} \mathrm{C}$ & & & & \\
SAS4A/SASSYS-1 & 525.87 & 509.52 & 506.40 & 520.26 & 546.13 \\
MUSA & 0.81 & 1.71 & 1.95 & 0.83 & 2.42 \\
Difference & & & & \\
Peak fuel centerline temperature, ${ }^{\circ} \mathrm{C}$ & 604.02 & 586.01 & 574.53 & 523.52 & 642.90 \\
SAS4A/SASSYS-1 & 603.38 & 584.10 & 573.44 & 522.88 & 641.22 \\
MUSA & 0.64 & 1.91 & 1.09 & 0.64 & 1.68 \\
\hline Difference & & & & & \\
\hline
\end{tabular}

In the second step, the transient behaviors during the ULOF accident predicted by the two codes were compared. With the loss of pumping power, the coolant flow in the primary circuit coasts down according to the programmed decay of the pump head. A flow-halving time of 7 seconds is assumed. Following the flow coast down, a natural circulation flow is established. Table 4 compares the MUSA and SAS4A/SASSYS-1 results at five time points up to 300 seconds into the transient. It can be seen that the MUSA results agree reasonably well with the SAS4A/SASSYS-1 reference solutions. The small differences, especially at the early stage of the transient, are due to the slightly overestimated flowrate of MUSA caused by the simplified model of the primary heat transport system. In the SAS4A/SASSYS-1 model, the cold pool is divided into two regions: upper and lower cold pool regions. The upper cold pool region is connected to the inlet plenum and the lower cold pool region through the primary pump and the 
cold pool transition segment, respectively. In the MUSA model, the cold pool is considered as a single compressible volume connected to the inlet plenum through the primary pump. At the steady state (or null transient), this difference in the cold pool model does not result in any difference in the flow rate since the lower cold pool is nearly stagnant and there is no flow through the cold pool transition segment. However, in the simulation of the ULOF accident, when the primary pump head starts to decrease during the ULOF accident, part of the coolant at the suction side of the primary pump flows towards the lower cold pool region instead of flowing through the primary pump. In the MUSA model, the coolant in the cold pool has a single flow path to the lower plenum through the primary pump, resulting a higher flow rate. It is noted that this would not affect the simulation of the loop-type primary heat transport system of SLFFR.

\section{Table 4}

Transient Results for ULOF Calculated by MUSA and SAS4A/SASSYS-1 Codes

\begin{tabular}{|c|c|c|c|c|c|}
\hline Time, sec & 30 & 50 & 100 & 150 & 300 \\
\hline \multicolumn{6}{|l|}{ Relative total power, $\%$} \\
\hline SAS4A/SASSYS-1 & 47.7 & 33.3 & 17.7 & 10.7 & 3.7 \\
\hline MUSA & 50.0 & 34.9 & 18.3 & 11.5 & 3.6 \\
\hline difference & -2.3 & -1.6 & -0.6 & -0.8 & 0.1 \\
\hline \multicolumn{6}{|l|}{ Relative total flow, $\%$} \\
\hline SAS4A/SASSYS-1 & 33.8 & 23.8 & 12.8 & 8.2 & 2.9 \\
\hline MUSA & 39.2 & 27.1 & 14.6 & 9.4 & 2.9 \\
\hline difference & -5.4 & -3.2 & -1.9 & -1.2 & 0.0 \\
\hline \multicolumn{6}{|c|}{ Coolant outlet temperature, ${ }^{\circ} \mathrm{C}$} \\
\hline SAS4A/SASSYS-1 & 590 & 589 & 589 & 582 & 585 \\
\hline MUSA & 581 & 587 & 585 & 580 & 582 \\
\hline difference & 9.45 & 1.76 & 3.77 & 2.35 & 2.79 \\
\hline \multicolumn{6}{|c|}{ Maximum fuel temperature, ${ }^{\circ} \mathrm{C}$} \\
\hline SAS4A/SASSYS-1 & 620 & 612 & 600 & 586 & 586 \\
\hline MUSA & 624 & 615 & 598 & 587 & 582 \\
\hline difference & -4.10 & -3.24 & 1.78 & -0.77 & 4.34 \\
\hline \multicolumn{6}{|c|}{ Maximum cladding temperature, ${ }^{\circ} \mathrm{C}$} \\
\hline SAS4A/SASSYS-1 & 599 & 595 & 590 & 582 & 586 \\
\hline MUSA & 587 & 591 & 587 & 581 & 585 \\
\hline difference & 12.37 & 3.83 & 2.78 & 0.93 & 1.47 \\
\hline \multicolumn{6}{|l|}{ Net reactivity, $\$$} \\
\hline SAS4A/SASSYS-1 & -0.229 & -0.256 & -0.249 & -0.231 & -0.248 \\
\hline MUSA & -0.201 & -0.242 & -0.234 & -0.202 & -0.247 \\
\hline difference & -0.028 & -0.014 & -0.015 & -0.028 & -0.001 \\
\hline
\end{tabular}

The slower decay of flowrate results in a delayed occurrence of the maximum coolant outlet temperature in the MUSA calculation. The MUSA solution shows the maximum coolant outlet temperature of $587^{\circ} \mathrm{C}$ at $\sim 50 \mathrm{~s}$, whereas the SAS4A/SASSYS-1 reference solution reaches the maximum value of $590{ }^{\circ} \mathrm{C}$ at $\sim 30 \mathrm{~s}$. After 50 seconds into the transient, the coolant, cladding and fuel temperatures predicted by the MUSA code show less than $5^{\circ} \mathrm{C}$ differences from the 
reference values. Since it is mainly due to the temperature changes, the feedback reactivity also agrees well with the reference value. The small difference in the net reactivity is mainly caused by the control rod driveline (CRDL) expansion component that shows a small difference due to the different sodium-mixing model in the upper region of the cold pool. The sodium in the cold pool of the MUSA model is considered perfectly mixed, while a stratification model for low flow conditions is used in the SAS4A/SASSYS-1 code. The perfect-mixing model underestimates the coolant temperature increase in the upper region of the cold pool and thus the amount of CRDL thermal expansion. As a result, the CRDL expansion reactivity predicted by the MUSA code is relatively less negative.

It is concluded from the above verification results that the computational models and their realizations in the MUSA code are reasonably good in describing the coupled neutronics and thermal-fluidic behaviors although minor deviations from the reference solutions are observed and identified to be due to the modeling simplifications employed in MUSA.

\section{Computational Models of SLFFR System}

The SLFFR is an innovative sodium cooled fast reactor for effective TRU burning. Detailed core design and performance characteristics are described in the companion paper (Jing, et al., 2016). The core design was developed to yield desirable reactivity feedback coefficients for passive shutdown of unprotected accidents. Table 5 summarizes the kinetic parameters and reactivity coefficients at the end of equilibrium cycle (EOEC).

\section{Table 5}

Kinetic Parameters and Reactivity Coefficients of SLFFR Core at EOEC

\begin{tabular}{lll}
\hline Parameter & unit & value \\
\hline Delayed neutron fraction & & 0.00200 \\
Prompt neutron lifetime & $\mu \mathrm{s}$ & 0.078 \\
Axial expansion coefficient & $\phi /{ }^{\circ} \mathrm{C}$ & -1.72 \\
Radial expansion coefficient & $\phi /{ }^{\circ} \mathrm{C}$ & 0.27 \\
Sodium density coefficient & $\phi /{ }^{\circ} \mathrm{C}$ & 0.23 \\
Sodium void worth & $\$$ & 7.65 \\
Doppler coefficient & $\phi /{ }^{\circ} \mathrm{C}$ & 0.00 \\
Fuel density coefficient & $\phi /{ }^{\circ} \mathrm{C}$ & -2.07 \\
Structure density coefficient & $\phi /{ }^{\circ} \mathrm{C}$ & 0.49 \\
Maximum GEMs worth & $\$$ & -1.11 \\
\hline
\end{tabular}

The loop-type arrangement of the primary heat transport system was selected for SLFFR design due to the relative compactness of the reactor vessel that supports the use of a rapid and frequent refueling system that does not require a large span across the reactor vessel head (Yang et al., 2015). The reactor core and the heat exchangers of DRACS are contained in a reactor vessel, and the primary pumps and IHXs are located in shielded cells outside the reactor vessel. The intermediate heat exchangers are established at the appropriate elevation to support natural circulation. The main design parameters of the SLFFR-1000 loop plant are summarized in the Table 6. 
Table 6

SLFFR-1000 Loop Plant Design Specifications

\begin{tabular}{ll}
\hline Parameter & Value \\
\hline Reactor power & $1000 \mathrm{MWt}, 390 \mathrm{MWe}$ \\
Coolant & Sodium \\
Coolant temperature, inlet/outlet & $450^{\circ} \mathrm{C} / 550^{\circ} \mathrm{C}$ \\
Coolant cover gas pressure & $0.107 \mathrm{MPa}$ \\
Total coolant flow rate & $7910 \mathrm{~kg} / \mathrm{sec}$ \\
Fuel type & Liquid metallic alloy \\
Charge fuel composition & 34.4 a/o TRU, 40.6 a/o Ce, and 25.0 a/o Co alloy \\
Core volume fractions, fuel/coolant/structure & $0.386 / 0.231 / 0.383$ \\
Fuel container material & Refractory Ta-10W alloy \\
Fuel container size & $1.8 \mathrm{~m}$ diameter, $1.08 \mathrm{~m}$ height \\
Fuel container pressure & $0.11 \mathrm{MPa}$ \\
Reactor vessel size & $6.35 \mathrm{~m}$ diameter, $8.5 \mathrm{~m}$ height \\
Heat removal capacity of DRACS & $100 \mathrm{MW}$ \\
IHX design & Straight tube, counter-flow \\
IHX heat transfer capacity & $250 \mathrm{MW}$ \\
Primary pump & centrifugal pump \\
Rated primary pump head & $84 \mathrm{~m}$ \\
\hline
\end{tabular}

The primary system of the SLFFR was modeled using the loop-type option in the MUSA code. The upper and lower sodium plena are modeled by two compressible volumes with and without cover gas, respectively. They are connected by two liquid segments. One represents the core channels and the other represents the hot leg, IHX, cold leg and the primary pump. The core is modeled by three parallel thermal-fluidic channels: hot, average and periphery channels. The primary system model is shown in Fig. 6.

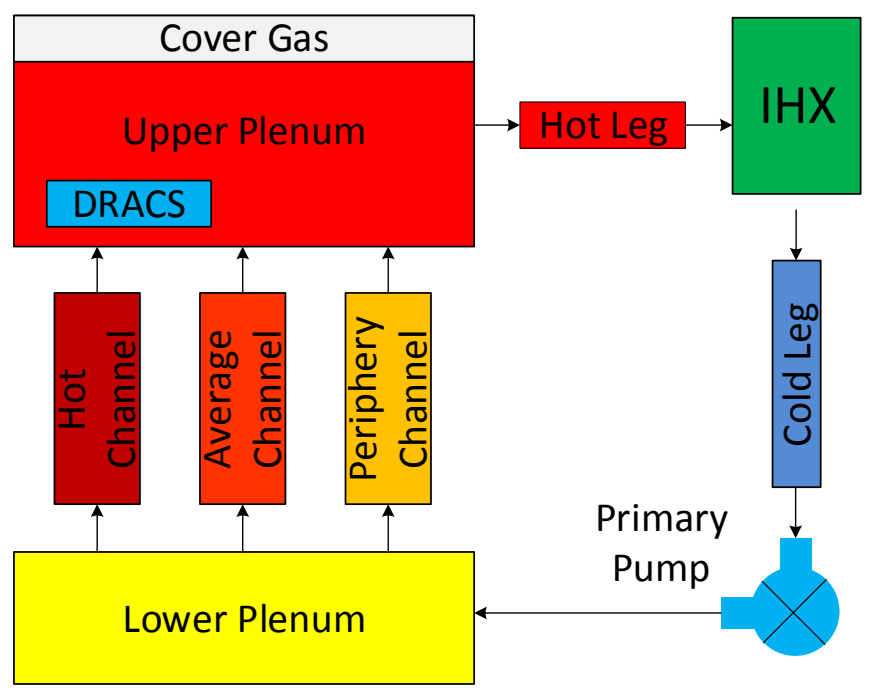

Fig. 6. Schematic MUSA Model of SLFFR Primary Heat Transport System 


\section{SLFFR Transient Analyses}

Three beyond-design-basis accidents (BDBAs) of primary importance for passive safety were analyzed at the equilibrium cycle condition: unprotected transient over power (UTOP), unprotected loss of flow (ULOF) and unprotected loss of heat sink (ULOHS). These sequences are extreme tests of the SLFFR to provide inherent self-protection against the consequences of the most severe accident initiators.

\subsection{UTOP}

For the UTOP accident, an extremely unlikely initiator was considered by assuming that all the control assemblies holding down the maximum excess reactivity were withdrawn instantaneously. Although the maximum excess reactivity to be held down by the control system is $0.167 \$$ at the BOL, a step reactivity insertion of $0.5 \$$ was assumed conservatively. It was assumed that the secondary heat transport system removes the heat at the nominal power rating.

Fig. 7 shows the transients of the coolant outlet, channel averaged structure, and channel averaged fuel temperatures in the hot channel as well as the coolant inlet temperature. Fig. 8 shows the transients of the total power and decay heat. The feedback reactivity components are shown in Fig. 9. It can be seen that the reactor reaches a new asymptotic state of the nominal power at elevated temperatures after 100 seconds into the transient. The positive reactivity inserted by the control rod run-out increases the power rapidly, which increases the fuel temperature almost adiabatically. The increased fuel temperature introduces a large negative reactivity due to thermal expansion of liquid fuel and thus reduces the rate of power increase. As a result, the power increases initially and then decreases back to the nominal power. The inserted figure in Fig. 8 shows the transient behavior of the total power in a much smaller time scale. As can be seen, the inserted positive reactivity increases the power rapidly to a local maximum of $\sim 163 \%$ of the nominal power at 0.0001 seconds. Subsequently, the competition of the negative prompt feedback due to the thermal expansion of liquid fuel and the delayed neutron source makes the power decrease to a local minimum of $\sim 122 \%$ of the nominal power at 0.0008 seconds and then increase gradually until $\sim 5$ seconds. At $\sim 5$ seconds into the transient, the power level reaches a maximum of $\sim 127 \%$ power and gradually decreases to the nominal power.

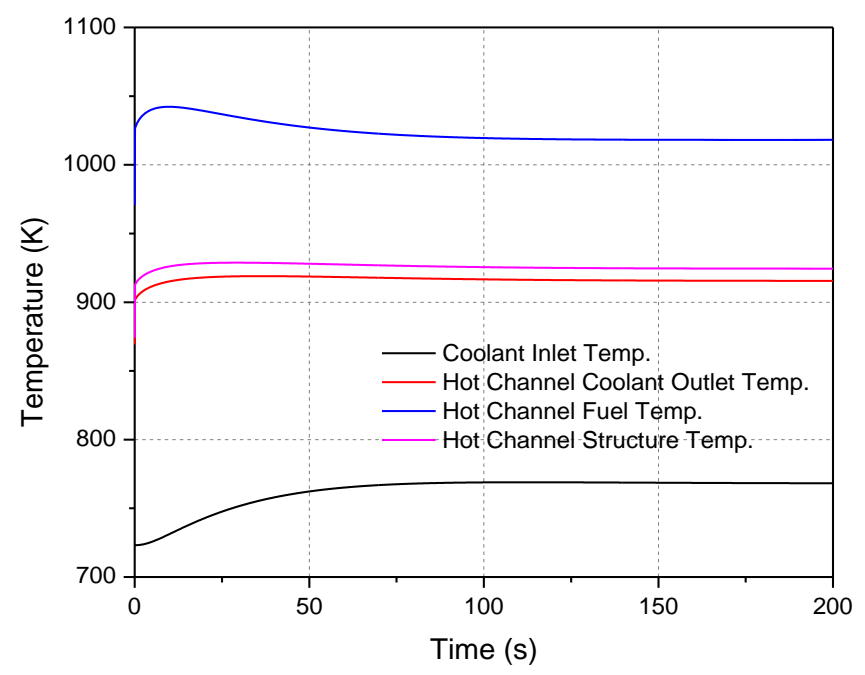

Fig. 7. Transient of Coolant Inlet and Hot Channel Temperatures for UTOP Accident 


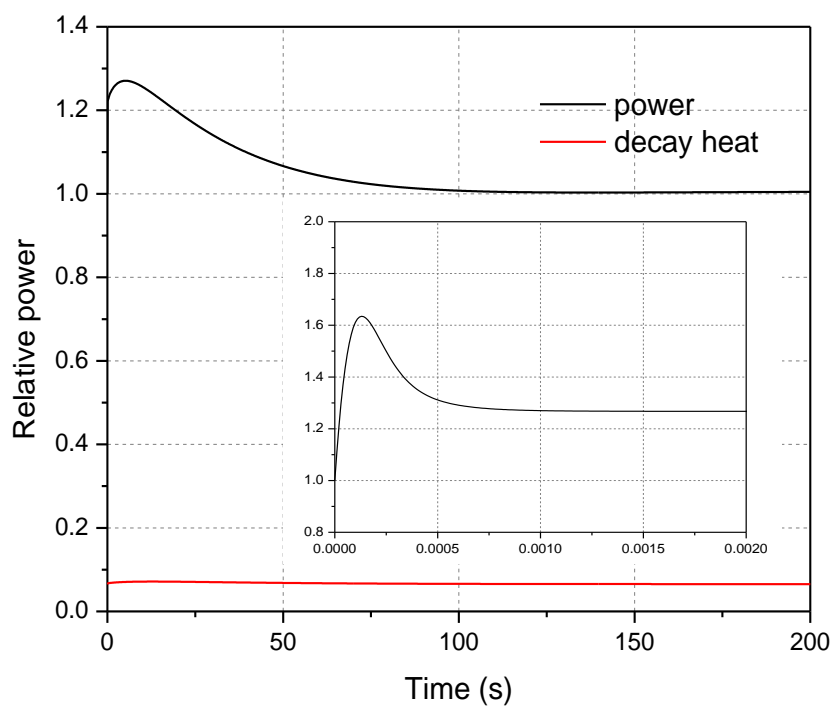

Fig. 8. Transient of Total Power for UTOP Accident

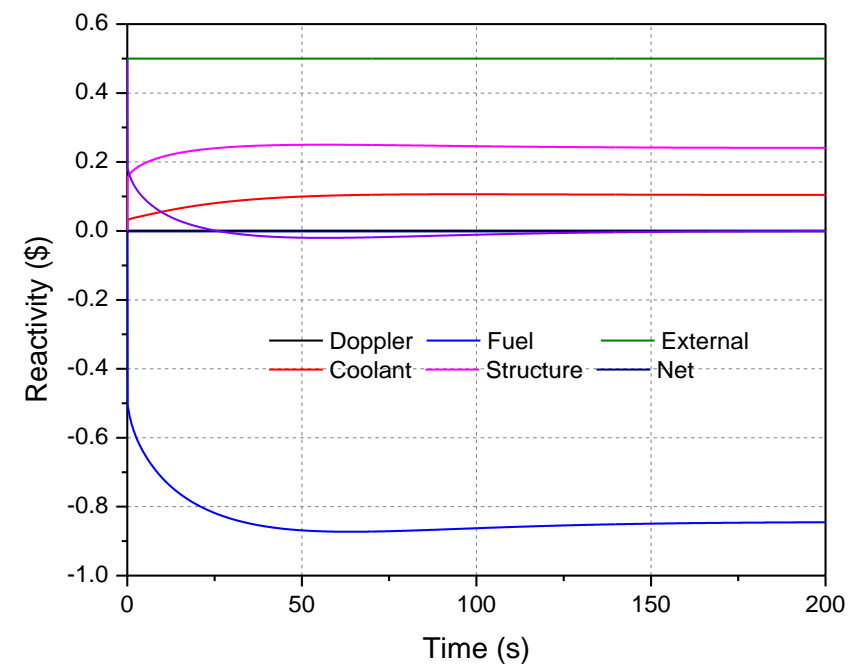

Fig. 9. Component-wise Reactivity Transients for UTOP Accident

Because of the increased power level for a fixed coolant flow rate, the coolant outlet temperature increases monotonically to an asymptotic value as shown in Fig. 7. The coolant inlet temperature also increases gradually to an asymptotic value because the heat removal by the secondary heat transport system is limited to the nominal rated power. As shown in Fig. 9, the increased fuel temperature introduces a large negative feedback, but the increased coolant and structure temperatures introduce positive reactivity feedbacks. The resulting net reactivity decreases gradually to zero at $\sim 26$ seconds into the transient. The fuel temperature keeps increasing due to the elevated power level. Thus, the net reactivity is negative until the power decreases to the nominal power and the reactor core reaches a new asymptotic state. The sum of the external reactivity of $0.5 \$$ and the positive reactivity insertion due to the increased coolant and structure temperatures is compensated for by the negative reactivity inserted by the increased fuel temperature. The asymptotic coolant inlet temperature is $768 \mathrm{~K}$. The asymptotic coolant 
outlet temperatures are $915 \mathrm{~K}, 878 \mathrm{~K}$ and $857 \mathrm{~K}$ for the hot, average and periphery channels, respectively. It is noted that the coolant outlet temperature of the hot channel has a margin of more than $280{ }^{\circ} \mathrm{C}$ to the sodium boiling point.

A parametric study was also performed to find the maximum reactivity insertion that can be passively controlled without reactor scram. Fig. 10 and Fig. 11 show the transients of the peak coolant temperature and the normalized power for a step reactivity insertion from $0.5 \$$ to $2.5 \$$. As expected, the peak coolant temperature and the peak power increase with increasing reactivity insertion. However, it can be seen that the peak coolant temperature stays below the sodium boiling temperature for a step reactivity insertion up to $\sim 2.5 \$$. In this case, the peak power increases up to 2.7 times of the nominal power within a short period and eventually decreases to the nominal power.

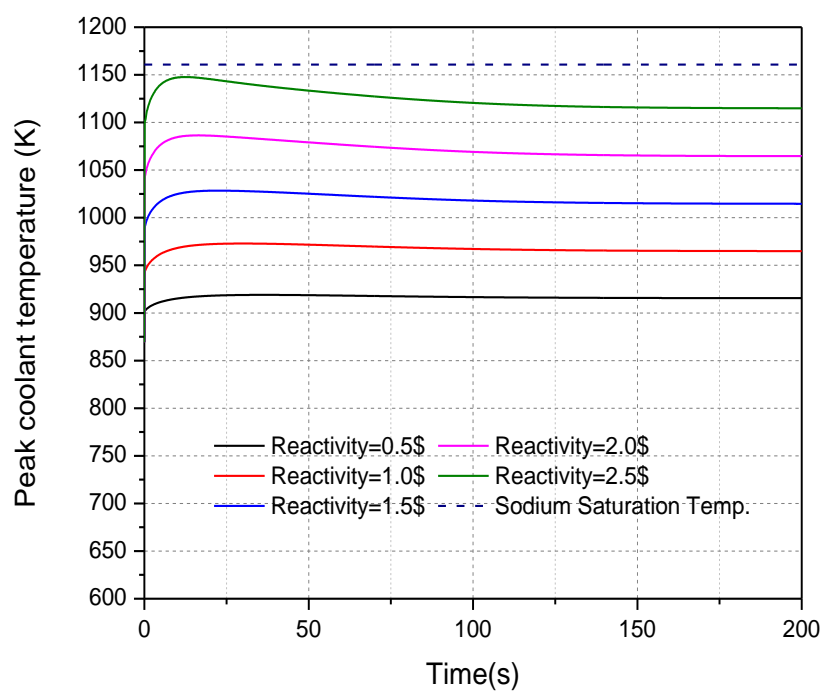

Fig.10. Transient of Peak Coolant Temperatures for UTOP Accidents with Different Reactivity Insertions

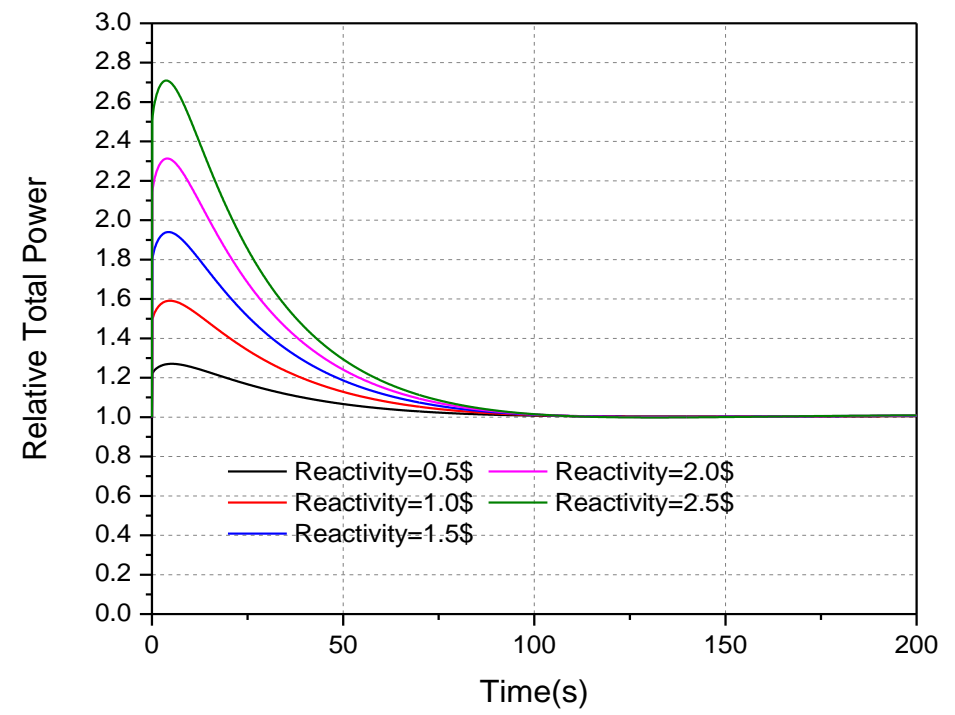

Fig. 11. Transient of Total Power for UTOP Accidents with Different Reactivity Insertions 


\subsection{ULOHS}

For the ULOHS accident, it is assumed that the steam turbine is tripped and thus the heat ejection by the balance of plant terminates. This increases the coolant inlet temperature monotonically while the flow rate and power remain constant. The raised coolant inlet temperature increases the structure and fuel temperatures. The fuel, structure, and coolant temperature coefficients are -2.07 cents $/{ }^{\circ} \mathrm{C}, 0.23$ cents $/{ }^{\circ} \mathrm{C}$, and 0.49 cents $/{ }^{\circ} \mathrm{C}$, respectively. As a result, the negative reactivity introduced by the fuel temperature and by the CRDL expansion overwhelms the positive reactivity from the coolant and structure density reductions. The net reactivity is negative and makes the power decrease.

Fig. 12 shows the time-dependent behaviors of coolant, fuel and structure temperatures in the hot channel. The power and decay heat transient and the component-wise reactivity transients are shown in Fig. 13 and Fig. 14, respectively. It can be seen that the total power of the ULOHS transient converges to the same level as the decay heat level, i.e., the SLFFR design has an inherent shutdown capability against a ULOHS accident. At 600 seconds into the transient, the decay heat reduces to $\sim 2.0 \%$ of full power although the fission power is almost zero. Since the heat removal capacity of DRACS is $1 \%$ of the rated power, the coolant temperature keeps increasing until the decay heat balances the heat ejection by the DRACS. The inlet and outlet pressure also gradually increase due to the thermal expansion of the sodium within the upper and lower plenum, which are considered as compressible volumes. This results in an increase of sodium saturation temperature from $1203 \mathrm{~K}$ to $1227 \mathrm{~K}$. Thus, the coolant outlet temperature would have a margin of $\sim 240^{\circ} \mathrm{C}$ to the sodium boiling point.

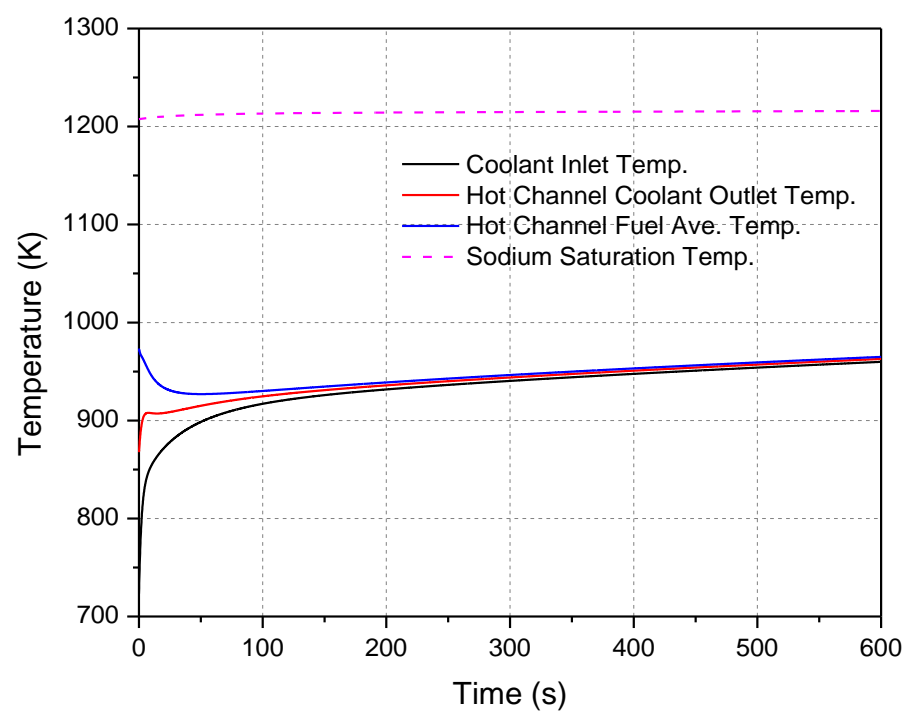

Fig. 12. Transient of Coolant Inlet and Hot Channel Temperatures for ULOHS Accident 


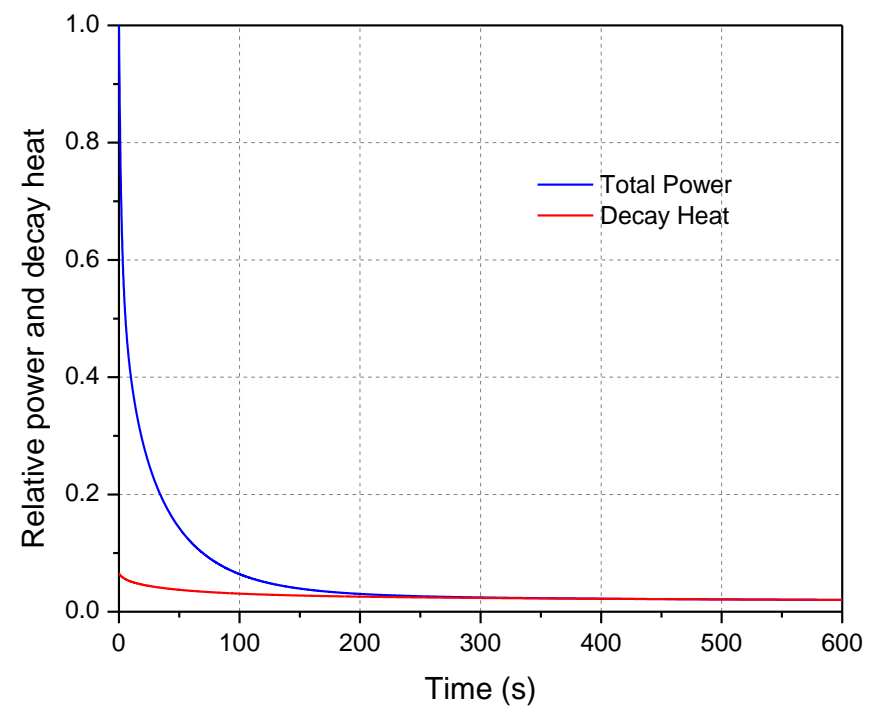

Fig. 13. Transients of Total Power and Decay Heat for ULOHS Accident

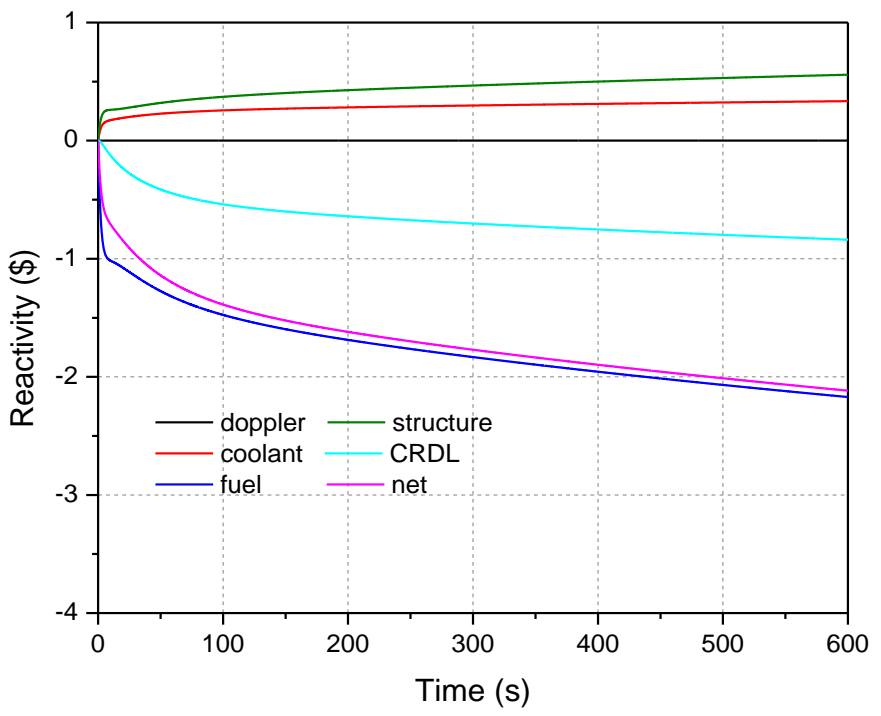

Fig. 14. Component-wise Reactivity Transients for ULOHS Accident

At the early stage of the transient, the average fuel temperature in the hot channel decreases while the hot-channel coolant outlet temperature increases. Initially, the power to flow ratio of the hot channel is 1.2 times larger than that of the average and periphery channel. Thus, the increment in the average fuel temperature relative to the average coolant temperature in the hot channel is also about 1.2 times larger than that in the average and periphery channel. Because of the negative feedback due to the increased coolant inlet temperature, the reactor power rapidly decreases to the decay heat level with time, and hence the coolant temperature rise across the core decreases in all three channels. The coolant temperature rise decreases more rapidly in the hot channel than in the average and periphery channels since the channel power reduction is proportional to the initial power. As a result, in the hot channel, the enhanced heat transfer rate from fuel to coolant exceeds the heat generation rate at the reduced power level, making the averaged fuel temperature decreases. At $\sim 40$ seconds, the hot channel averaged fuel temperature 
reaches the minimum of $944 \mathrm{~K}$ and starts to increase due to the increased coolant inlet temperature. At 600 seconds into the transient, the core temperatures are converged to $\sim 980 \mathrm{~K}$.

\section{3. $U L O F$}

In the ULOF accident, it is assumed that all the power to the primary pumps is lost and the reactor fails to scram. The loss of power to the primary pumps leads to a flow coast-down, governed by the mechanical inertia of the pumps. In this analysis, a flow-halving time of 8 seconds is assumed.

Fig. 15 shows the reactivity transients for the ULOF accident. It can be seen that the GEMs introduce a large negative reactivity rapidly through enhanced leakage. At around 20 seconds, the GEM worth reaches the maximum value in magnitude of $1.1 \$$. The total power decreases due to the negative reactivity introduced by GEMs. However, the total flow decreases faster than the decrease of the total power as shown in Fig. 16. The outlet coolant temperature starts to increase. At around $\sim 58$ seconds into the transient, the coolant outlet temperatures in the hot, average and periphery channels reach the maximum values of $1142 \mathrm{~K}, 1030 \mathrm{~K}$ and $971 \mathrm{~K}$, respectively. The peak coolant temperature in the hot channel has a margin of around $70 \mathrm{~K}$ to the sodium boiling point as shown in Fig. 17.

The fuel temperature decreases due to the rapidly reduced total power, which introduces a large positive reactivity compensating for part of the negative reactivity induced by the GEMs, CRDL expansion and structural material density feedback. At the asymptotic state, the negative reactivity induced by GEMs, CRDL expansion, structure density change and coolant density change is fully compensated for by the positivity reactivity due to the decreased fuel temperature, and the net reactivity approaches to zero. The pump head decreases almost to zero after around 50 seconds, and from this moment, the flow is driven mainly by the natural circulation. The fully established natural circulation flow rate is estimated to be $5.4 \%$ of the nominal flow rate.

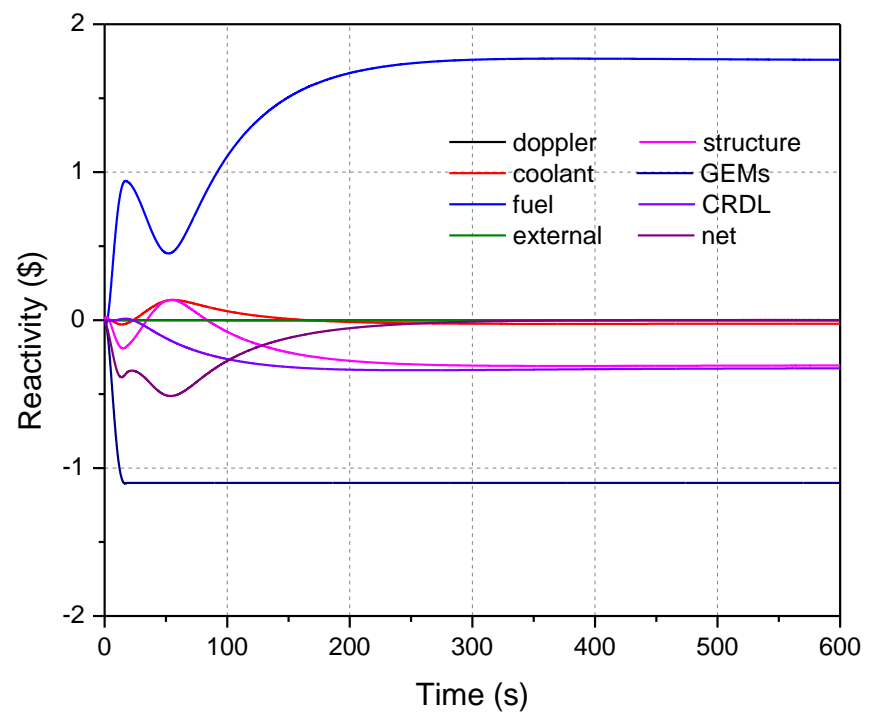

Fig. 15. Component-wise Reactivity Transients for ULOF Accident 


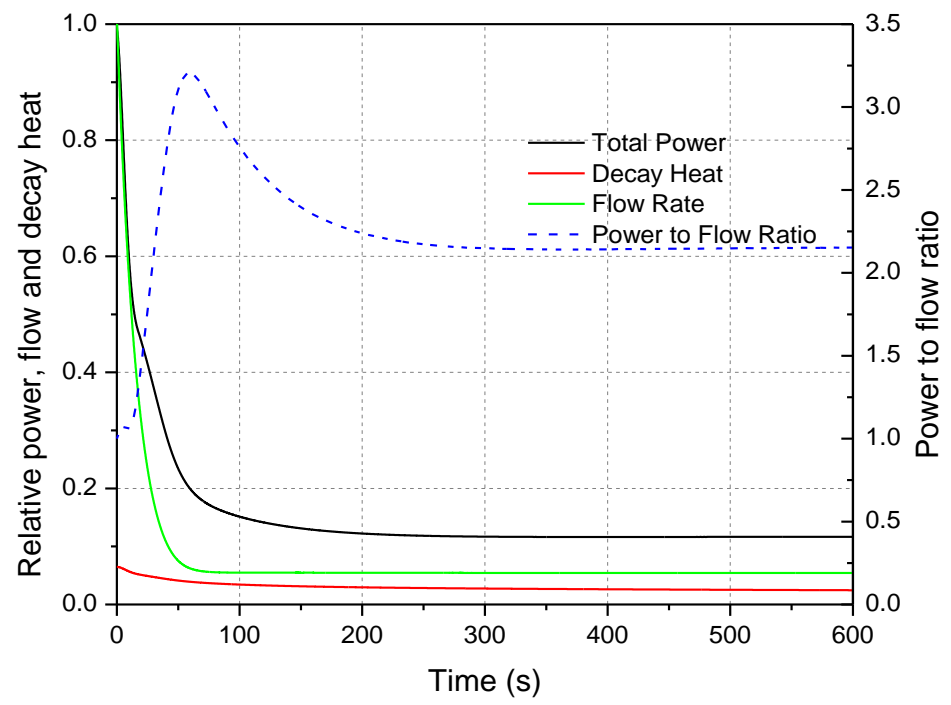

Fig. 16. Transients of Total Power, Decay Heat, Flow Rate and Power to Flow Ratio for ULOF Accident

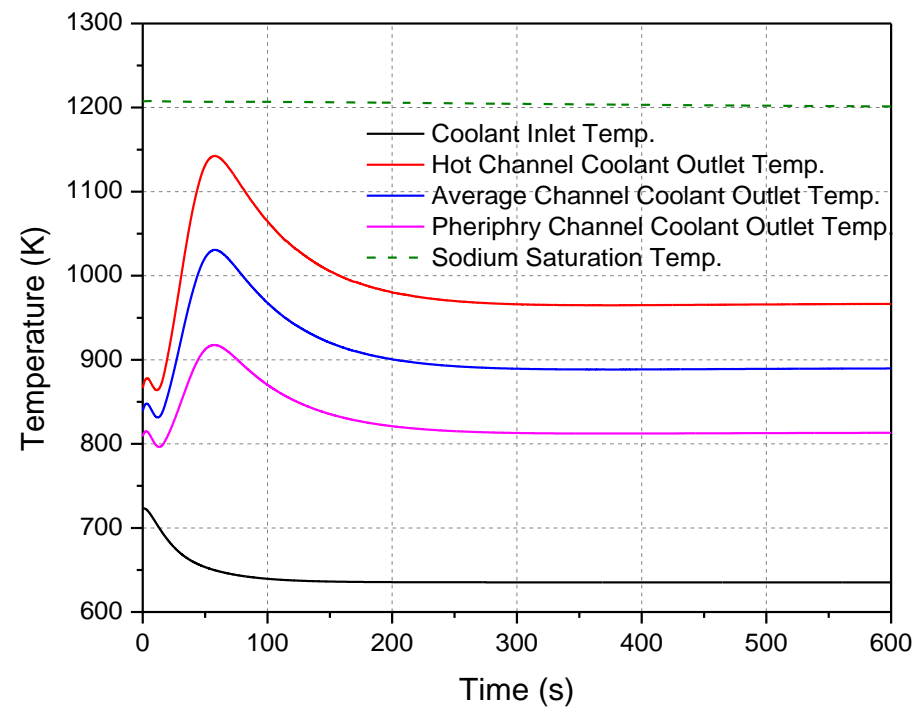

Fig. 17. Transients of Coolant Temperatures for ULOF Accident

\section{Conclusions}

Safety characteristics have been evaluated for the latest design of 1000 MWt SLFFR with zero TRU conversion ratio. In order to model the geometrical configuration and reactivity feedback mechanisms unique to SLFFR, a multi-channel safety analysis code named MUSA was developed. The thermal-fluidic behavior of the core is described by representing the core with one-dimensional parallel channels. The primary heat transport system is modeled by connecting compressible volumes by liquid segments. A point kinetics model with six delayed neutron groups is used to represent the fission power transients. The decay heat is calculated using the ANS decay heat standards ANSI/ANS-5.1. The reactivity feedback is estimated by combining the temperature and density variations of liquid fuel, structural material and sodium coolant with 
the corresponding axial distributions of reactivity worth in each individual thermal-fluidic channel.

Preliminary verification tests of the MUSA code were performed by a code-to-code comparison with the well-validated safety analysis code SAS4A/SASSYS-1. The steady-state operating conditions and the ULOF accident scenario of ABTR were analyzed using the MUSA code, and the results were compared with the reference solutions obtained with the SAS4A/SASSYS-1 code system. The steady-state and transient test results indicated that the computational models and their realizations in the MUSA code are reasonably good in describing the coupled neutronics and thermal-fluidic behaviors although minor deviations from the reference solutions were observed and identified to be due to the modeling simplifications employed in MUSA.

Using the MUSA code, the safety characteristics of the SLFFR design were investigated for three beyond design basis accidents: UTOP, ULOHS, and ULOF accidents. The transient analysis results indicated that the SLFFR design has a passive shutdown capability for these unprotected accidents scenarios. All these transient scenarios were terminated with no sodium boiling. The thermal expansion of liquid fuel provides a sufficiently large negative feedback reactivity for passive shutdown of UTOP and ULOHS. During the ULOF accident, the GEMs installed at the core periphery respond quickly to the primary pump head loss and introduce a large negative reactivity so that the accident is terminated passively with a sufficient margin to the sodium boiling point.

One major concern of the SLFFR design is the possibility of coolant tube failure that would lead to the leak of liquid fuel into the primary coolant system. The potential mechanisms for coolant tube failure need to be studied in more detail, including the tube corrosion in contact with high temperature TRU-Ce-Co fuel. A study on the manufacturing technology to increase the reliability of coolant tubes is also required. In addition, it would be worthwhile to study different geometrical arrangements of fuel and coolant to minimize the possibility of fuel leak to the coolant system.

\section{Acknowledgements}

This research was performed using funding received from the DOE Office of Nuclear Energy's Nuclear Energy University Programs.

\section{References}

ANS Standards Committee Working Group, 2005. Decay Heat Power in Light Water Reactors. ANSI/ANS-5.1-2005, American Nuclear Society, La Grange Park, Illinois.

Cahalan, J.E. and Wei, T., 1990. Modeling developments for the SAS4A and SASSYS computer codes. Proc. Int. Fast Reactor Safety Meeting, Snowbird.

Cahalan, J.E., et al., 1994. Advanced LMR Safety Analysis Capabilities in the SASSYS-1and SAS4A Computer Codes. Proc. Int. Topical Meeting on Advanced Reactors Safety, Pittsburgh.

Campbell, L. R., et al., 1986. Reactivity Worth of Gas Expansion Modules (GEMs) in the Fast Flux Test Facility. Trans. Am. Nucl. Soc., 53, 457. 
Chang, Y. I., Finck, P. J., and Grandy, C., 2006. Advanced Burner Test Reactor Preconceptual Design Report. ANL-ABR-1 (ANL-AFCI-173), Nuclear Engineering Division, Argonne National Laboratory, September 5.

Courant, R., Friedrichs, K., and Levy, H., 1967. On the Partial Difference Equations of Mathematical Physics. IBM Journal of Research and Development, 11, pp 215-234.

Dunn, F. E., Fanning, T. H., and Cahalan, J. E., 2006. Preliminary Safety Evaluation of the Advanced Burner Test Reactor. ANL-AFCI-172, Nuclear Engineering Division, Argonne National Laboratory, September 15.

Fanning, T. H., et al., 2012. The SAS4A/SASSYS-1 Safety Analysis Code System. ANL/NE12/4, Nuclear Engineering Division, Argonne National Laboratory, January 31.

Jing, T. Yang, G., Jung, Y. S. and Yang, W. S., 2015. An Optimized Core Design of Passively Safe Liquid Fuel Reactor SLFFR for TRU Burning. Trans. Am. Nucl. Soc., 113, 1095-1098.

Jing, T., Jung, Y. S., and Yang, W. S., 2016a. Passive Safety Characteristics of Stationary Liquid Fuel Fast Reactor (SLFFR). Proc. of PHYSOR 2016, Sun Valley, ID, May 1-5, 2016.

Jing, T., Yang, G., Jung, Y. S., and Yang, W. S., 2016b. Stationary Liquid Fuel Fast Reactor SLFFR - Part I: Core Design. Companion paper submitted to Nuclear Engineering and Design.

Lyon, R. N., 1951. Liquid Metal Heat Transfer Coefficients. Chem. Eng. Prog. Vol. 47, No. 2, pp.75-79.

Ott, K.O. and Neuhold R. J., 1985. Introductory Nuclear Reactor Dynamics. American Nuclear Society, La Grange Park, Illinois.

RELAP5 Development Team, 2001. RELAP5/MOD3.3 Code Manual. Nuclear Safety Analysis Division, Information Systems Laboratories, Inc., Rockville, MD.

Smith, M. A., Adams, C., Yang, W. S., and Lewis, E. E., 2013. VARI3D \& PERSENT: Perturbation and Sensitivity Analysis. ANL/NE-13/8, Argonne National Laboratory.

Smith, K. S., 1979. An Analytic Nodal Method for Solving the Two-Group, Multidimensional, Static and Transient Neutron Diffusion Equations. M.S. and N.E. Thesis, MIT.

Todreas, N. E. and Kazimi, M. S., 2012. Nuclear Systems Vol. I: Thermal Hydraulic Fundamentals, Chapter 4, 2nd Ed. CRC Press, New York.

Vota, A. V, Curlee, Jr., N. J., and Henry, A. F., 1969. WIGL3 - A Program for the Steady-State and Transient Solution of the One-Dimensional, Two-Group, Space Time Diffusion Equations Accounting for Temperature, Xenon, and Control Feedback. WAPD-TM-788, Bettis Atomic Power Laboratory.

Yang, W. S. and Grandy, C., 2012. Stationary Liquid Fuel Fast Reactor Concept for TRU Burning. Trans. Am. Nucl. Soc., 107, 1045.

Yang, W. S., Shi, S. and Grandy, C., 2013. Core Design Study of Stationary Liquid Fuel Fast Reactor for TRU Burning. Proc. ICAPP 2013, Jeju Island, Korea, April 14-18.

Yang, W. S. et al., 2015. Final Report on Stationary Liquid Fuel Fast Reactor. PU/NE-15/08, Purdue University. 